\title{
Neoclassical Growth and the Natural Resource Curse Puzzle
}

\author{
María Dolores Guillo* \\ guillo@ua.es
}

\author{
Fidel Perez-Sebastian* \\ F.Perez-Sebastian@hull.ac.uk
}

\author{
February 2015 \\ Published in Journal of International Economics
}

\begin{abstract}
We advance a novel mechanism that helps to explain the puzzling evidence on the natural resource curse. The new channel arises in a standard dynamic Heckscher-Ohlin model composed of small-open economies that take international output prices as given. Within this framework, a more capital-intensive primary sector implies that naturalresource abundant economies grow more slowly along the adjustment path. This effect might be only temporary because the natural input also affects long-run income, and not necessarily in the same direction as transitional growth. We produce quantitative results that show that the new mechanism can account for a significant fraction of the observed output growth gap between resource rich and resource poor U.S. states.
\end{abstract}

JEL Classification: O11, O13, O41, F11, F43.

(C) 2015, Elsevier. Licensed under the Creative Commons Attribution-NonCommercialNoDerivatives 4.0 International http://creativecommons.org/licenses/by-nc-nd/4.0/

${ }^{*}$ Guilló: Department of Economics and IUDESP, Universidad de Alicante. Perez-Sebastian: Department of Economics, Universidad de Alicante; and Hull University Business School. Postal address: AP Correos 99, Universidad de Alicante, E-03080 Alicante, Spain. We thank Jaime Alonso-Carrera, Francesco Caselli, Oded Galor, Delfim Gomes Neto, Rachel Ngai, Xavier Raurich, Diego Restuccia, Pierre Sartre, David Weil, and seminar participants at the 2007 SED meeting in Prague, the University of Barcelona, Brown University, the Richmond Fed, and the University of Vigo for helpful comments. This research was partially supported by the Spanish Ministry of Science and Innovation (ECO2012-36719 and ECO2013-43119-P), the Generalitat Valenciana (PROMETEO/2013/037) and by the Instituto Valenciano de Investigaciones Económicas. 


\section{Introduction}

Recent studies such as Sachs and Warner (1997, 1999, 2001) and Gylfason (2001) argue that resource abundant countries grow more slowly and lag, on average, behind countries with less resources. This puzzling phenomenon has been labeled as the natural resource curse. Frankel (2010) and van der Ploeg (2011) summarize the literature, pointing out two main explanations: market mechanisms, and political channels. The former ones state that sectors that are intensive in natural resources could be dead-end activities because of, for example, the high volatility and secular decline of the international prices of these commodities. The dead-end nature can be also a consequence of a crowding out effect on other activities such as manufacturing that potentially contribute more intensively to technological change. The latter channels, in turn, imply that natural riches can offer an easy source of wealth for politicians and powerful elites, leading to the establishment of bad institutions, and frequent wars for their control.

Nevertheless, the evidence is far from being conclusive. For example, while some resourcerich countries do poorly, others like Norway do very well economically. Perhaps more importantly, some evidence that gives support to the curse is difficult to explain with existing theories. Papyrakis and Gerlagh (2007), for instance, find that there is a statistically significant negative relationship between resource abundance and economic growth for 49 U.S. states; it is unlikely that changes in international prices, or institutional and political system differences are behind the result. This justifies the need for other theories that do not rely on those mechanisms.

In this paper, we advance a new explanation based on a simple open-economy two-sector neoclassical growth model. The novel theory explains why higher resource endowments can result in lower growth in the less resource-intensive sector, making the whole economy grow more slowly. The key is the existence of differences in input shares in different production activities. This allows the effect of resources to evolve along with the economy, rather than being a simple fixed total factor productivity effect.

More specifically, we introduce a natural input into a dynamic Heckscher-Ohlin model of international trade and growth. The economy is composed of a large number of small open economies. Each country has the production structure of the two-sector neoclassical growth model with two goods - one primary and the other non-primary - that are traded internationally. The two sectors employ capital and labor as factors of production with different intensities. In addition, a fixed natural resource and the primary product are employed as inputs by the primary and non-primary sectors, respectively. All economies have identical preferences and production technologies, but they may differ regarding the natural endow- 
ment. Some countries that we call the developed world have already reached the steady state, while other countries have not.

The main prediction of the model is that, under diversified production equilibrium, in small-open economies, or economies that are price takers in international markets, the natural input negatively affects economic growth through the convergence speed. The reason is that the economy-wide capital weight is affected by the allocation of resources between sectors. In particular, given that primary activities are more physical capital intensive, the economywide capital share rises with the natural endowment because of the increasing weight of the primary sector. The implication of this increase in the capital share is that the interest rate falls more slowly towards its long-run value, thus decreasing the investment rate in capital accumulation and, therefore, the rate of economic growth.

We also find that the negative growth effect in the model might be only temporary: a larger stock of natural inputs has a positive effect on long-run income if the primary activity is the less labor intensive activity. As a consequence, the long-run and transitional effects can run in opposite directions. This is an interesting result of the model that has important implications for growth regressions because it can make natural resources show up in the data as a curse for economic growth even when they positively affect steady-state output. Furthermore, this result is consistent with recent work by Alexeev and Conrad (2009) who find that natural riches have a positive effect on income per capita.

We perform a quantitative exercise to assess the theory and show that these effects, although not large, can be significant. In the calibrated economy, when the natural endowment triples, income per capita can increase up to 12 percent, and the convergence speed falls more than 1.5 percentage points. More importantly, focusing on the sample of U.S. states employed by Papyrakis and Gerlagh (2007), we find that our novel mechanism contributes to generate a resource curse over the time horizon considered by these authors, 1986-2000. In particular, the model can explain most of the observed growth disparities as a consequence of differences in both output distance to the long-run trend and natural endowments. Moreover, differences in the natural endowments are estimated to explain about 11 percent of the dispersion in growth rates across U.S. states.

The rest of the paper is organized as follows. Section 2 carries out a review of the related literature. The model's economic environment is described in Section 3. Section 4 analyzes the impact of natural inputs on a small-open developing economy. The numerical exploration is in Section 5. Section 6 presents the conclusion. 
Figure 1: Growth and natural resource abundance 1970-1989

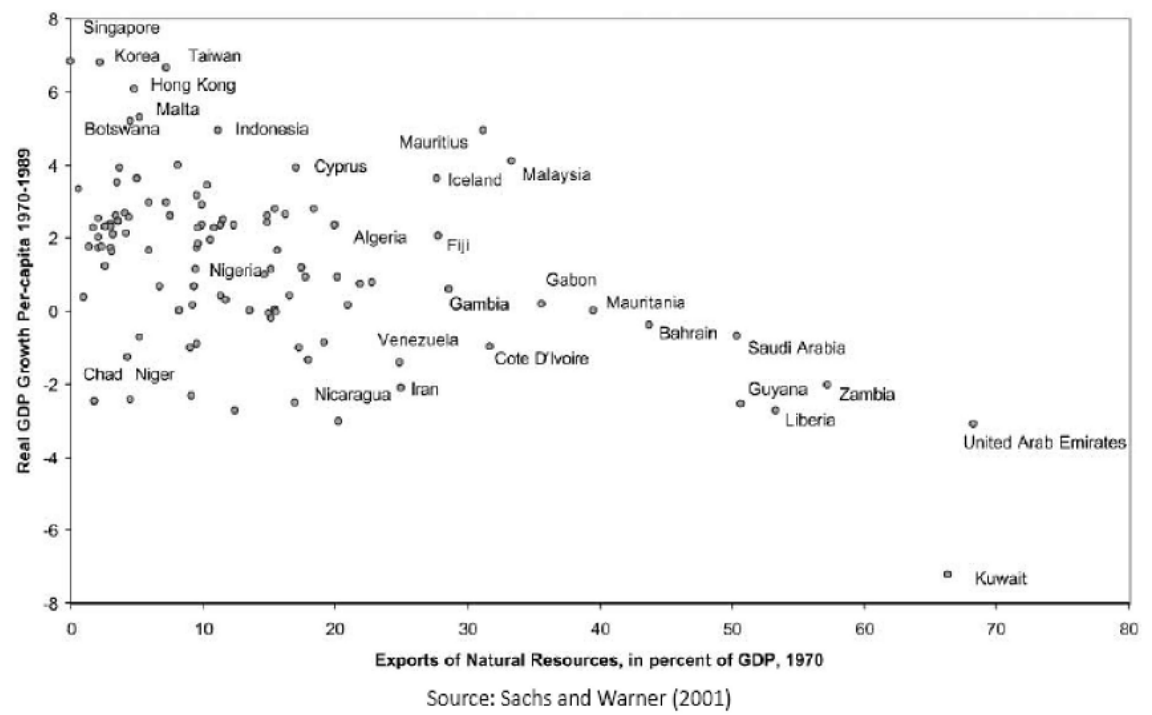

\section{Review of the Related Literature}

Frankel (2010) and van der Ploeg (2011), among others, provide a detailed review of the evidence and theories about the natural resource curse. This section focuses on some articles that offer observational evidence that establishes the puzzle, and reviews the literature that we believe is closest to our research.

Sachs and Warner $(1999,2001)$ are among the most important works that offer evidence in favor of the natural resource curse. In particular, they show that the share of exports of primary products in GDP displays a negative correlation with posterior growth after controlling for several variables that include economic, geographical, and climate proxies. Their result is illustrated in Figure 1. We observe that countries with lower shares of primaryproduct exports in 1970 generated, on average, faster GDP per-capita growth from 1970 to 1989; this negative correlation is significant at the $5 \%$ level.

The result has been found as well by other authors employing a variety of measures of resource abundance. Gylfason (2001) shows that the population's level of education, a variable closely related to the level of economic development, is negatively related to the share of natural capital in national wealth. Isham et al. (2005) obtained evidence that oil, minerals such as copper and diamonds, and plantation crops such as coffee and cocoa are negatively related with institutional quality measures that are, in turn, strongly associated to economic growth.

There exist several theoretical explanations for this puzzle. Among the earliest ones, 
Bhagwati's (1958) immiserizing growth theory emphasizes the negative effect on a country's income of the change in the terms of trade that follows after the discovery of natural riches. In the same vein - that is, through changes in international prices - Corden and Neary (1982) show that the structural problems that arise from the discovery of a natural resource (the called 'Dutch disease') can be the consequence of appreciations in the exchange rate.

In other models, natural resources discourage the accumulation of capital inputs necessary to foster economic growth. Matsuyama (1992), for example, considers that the manufacturing sector is characterized by a learning by doing mechanism that promotes growth, while the primary sector that uses natural resources is a stagnant activity. Adamopoulos (2008) and Galor et al. (2008) emphasize that land-ownership inequality can delay industrialization through its effects on the import of intermediate goods used in industry and on the implementation of human-capital promoting institutions, respectively. Gaitan and Roe (2012) argue that the phenomenon can be explained by an increase in trade revenues that induces a reduction in capital investment in the resource-abundant country.

On the political economy side, Hodler (2006) and Caselli and Cunningham (2009), among others, offer frameworks in which a natural resource curse can appear via internal struggle for ownership. Finally, a simpler explanation is provided by Rodríguez and Sachs (1999, p. 278): they argue that "resource-rich countries may grow more slowly because they are likely to be living beyond their means".

The natural resource curse literature can be, however, very controversial. In particular, not all authors actually find the existence of a curse. For an example of this see James (2015) who argues that - if you measure things correctly - there is not much of a resource curse after all. Other examples are Mehlum et al. (2006) and Alexeev and Conrad (2009). The former provides evidence that in countries with good (bad) institutions natural inputs are a blessing (curse) for economic growth. The latter paper, in turn, finds that natural inputs have a positive effect on income per capita. Similarly, Brunnschweiler and Bulte (2008) conclude from their statistical analysis that the apparent paradox may be a red herring. ${ }^{1}$

In addition, as explained in the introduction, some articles such as Papyrakis and Gerlagh (2007) provide evidence that gives support to the curse within a context that disagrees with existing theories. Our framework does not rely on the above mechanisms; final-goods prices remain constant, total factor productivity growth can be the same across activities, and political institutions are absent. The focus is on the effects that are a consequence of Rybczynski-type mechanisms.

This work is also related to the literature on multi-sector models of international trade and

\footnotetext{
${ }^{1}$ Van der Ploeg and Poelhekke (2010), however, argue that this last result suffers from endogeneity problems.
} 
growth that include Ventura (1997), Mountford (1998), Atkeson and Kehoe (2000), Bajona and Kehoe (2006, 2010), Galor and Mountford (2008), Guilló and Perez-Sebastian (2007), and Stefanski (2014). We concur with them that the main results are driven by the flow of resources across domestic sectors. Unlike in this work, the first five articles use more or less standard versions of the two-sector neoclassical framework that do not include natural resources. Neither does the Galor and Mountford (2008) study that focuses on the fertility and human capital dimensions. In Guilló and Perez-Sebastian (2007) the model is similar, but it only analyzes the effects of fixed sector-specific inputs on steady-state income. Finally, Stefanski (2014) considers trade of energy products to analyze the relationship between oil prices and the structural transformation process.

\section{The Environment}

Consider a world economy consisting of a large number of small open economies that have a constant and equal-size population. These economies share identical fundamentals with the exception of their per-capita natural resource endowment. There are two goods and four inputs of production, all of them traded in perfectly competitive markets. The production of primary goods needs capital, labor, and natural resources. The non-primary sector employes labor, capital and an intermediate good that comes from the primary sector's output. Capital and labor move freely between sectors. There is free trade in goods, but international movements of inputs are prohibited. The total stock of the natural input in the economy is non-reproducible. For simplicity, we assume that its supply is fixed over time and equal to $N$.

The last assumption deserves some comments. A fixed supply does not apply in reality to all kinds of natural resources. More specifically, the literature considers two main types of natural riches: point-source and diffuse-source. The former ones locate in specific geographical areas, are non-renewable, and suffer from systematic depletion; examples include minerals and fuels. The diffuse-source, in turn, are renewable, and can be found pretty much everywhere, like land, sunlight, air, wind, or water. The assumption of being in fixed supply is more appropriate for the second type of natural riches.

Infinitely-lived individuals discount future utility at the factor $\rho$. All individuals possess identical preferences defined only over consumption of primary $\left(c_{a t}\right)$ and non-primary $\left(c_{m t}\right)$ goods. In particular, the preferences of the representative consumer are given by

$$
\sum_{t=0}^{\infty} \rho^{t}\left[\varphi \ln c_{a t}+(1-\varphi) \ln c_{m t}\right], \quad \rho, \varphi \in(0,1) .
$$

Individuals offer labor services and rent capital and natural resources to firms. The stock $N$ 
is uniformly distributed across all individuals. Since in each period international trade must be balanced, each consumer faces the following budget constraint

$$
c_{a t}+p_{t}\left(c_{m t}+x_{t}\right)=r_{k t} k_{t}+r_{n t} n+w_{t}
$$

where the evolution of the capital stock per capita is governed by

$$
k_{t+1}=(1-\delta) k_{t}+x_{t}
$$

In the above expressions, $x_{t}$ is the per capita demand of non-primary goods used for investment at date $t$, whose price is $p_{t} ; r_{k t}, r_{n t}$, and $w_{t}$ are, respectively, the rental rates on capital, natural resources, and labor; $n$ and $k_{t}$ denote the amount of the natural input and capital owned by each individual, respectively. The primary good is the numeraire.

Consumers in each country will maximize (1) subject to (2) and (3), taking as given the world output prices and the domestic rental rates on production factors. As a result the optimal allocation of resources, consumption expenditures will be split between the two goods according to the rule:

$$
\frac{c_{a t}}{c_{m t}}=\left(\frac{\varphi}{1-\varphi}\right) p_{t}
$$

In addition, the Euler equation corresponding to this dynamic programing problem is

$$
\frac{c_{t+1}}{c_{t}}=\frac{p_{t+1}}{p_{t}} \rho\left(\frac{r_{k t+1}}{p_{t+1}}+1-\delta\right)
$$

where $c_{t}=c_{a t}+p_{t} c_{m t}$ is total aggregate consumption per capita. Equation (5) is standard: it says that the growth rate of consumption depends on the present-utility value of the rate of return to saving. This return reflects that giving up a unit of present consumption allows buying $1 / p_{t}$ units of the investment good today that, after contributing to the production process, will covert themselves tomorrow in $\left(1+r_{k t+1} / p_{t+1}-\delta\right)$ units that can be sold at a price $p_{t+1} \cdot^{2}$

In each country, production of the primary good $\left(Y_{a t}\right)$ is given by

$$
Y_{a t}=A_{t} K_{a t}^{\alpha} N_{t}^{\beta} L_{a t}^{1-\alpha-\beta}=A_{t} L_{a t} k_{a t}^{\alpha} n_{a t}^{\beta}, \quad \alpha, \beta, \alpha+\beta \in(0,1) .
$$

And the production of non-primary goods $\left(Y_{m t}\right)$ by

$$
Y_{m t}=B_{t} K_{m t}^{\theta} Z_{t}^{\gamma} L_{m t}^{1-\theta-\gamma}=B_{t} L_{m t} k_{m t}^{\theta} z_{m t}^{\gamma}, \quad \theta, \gamma, \theta+\gamma \in(0,1)
$$

\footnotetext{
${ }^{2}$ We could introduce a minimum consumption level of primary goods in household's preferences, expression (1). In fact, minimum consumption can make the natural input to positively affect transitional growth at early stages of the adjustment process, as Irz and Roe (2005) show. This survival consumption requirement would not, however, affect our results. The reason is that its effect disappears asymptotically as the economy approaches the steady state. Therefore, it should have a negligible impact on steady-state outcomes and on the asymptotic speed of convergence.
} 
In the above expressions, $K_{i t}$ and $L_{i t}$ denote the amount of capital and labor devoted to the production of good $i$ in period $t$, respectively. $N_{t}$ represents the amount of the natural resource used in the production of primary goods and $Z_{t}$ the amount of the primary output employed in the production of $m$ goods. Relative input uses are defined as $k_{i t}=K_{i t} / L_{i t}$, $n_{i t}=N / L_{i t}$, and $z_{i t}=Z_{t} / L_{i t}$. Finally, $A_{t}$ and $B_{t}$ are positive efficiency parameters common to all countries that grow at constant rates $G_{A}$ and $G_{B}$, respectively.

Let us denote the fraction of labor employed in the production of good $i$ by $l_{i t}=L_{i t} / L_{t}$. Notice that because consumers are alike, the amount of capital owned by each individual will equal the country's capital-labor ratio. Hence, the constraints on labor, capital and natural resource inputs within a country can be written as follows:

$$
\begin{gathered}
l_{a t}+l_{m t}=1, \\
l_{a t} k_{a t}+l_{m t} k_{m t}=k_{t}, \\
l_{a t} n_{a t}=n .
\end{gathered}
$$

Firms in each country will maximize profits taking as given world prices and the domestic rental rates on production factors. From production functions (6) and (7), production efficiency implies that

$$
\begin{aligned}
r_{k t} & =\alpha A_{t} k_{a t}^{\alpha-1} n_{a t}^{\beta}=p_{t} \theta B_{t} k_{m t}^{\theta-1} z_{m t}^{\gamma}, \\
r_{n t} & =\beta A_{t} k_{a t}^{\alpha} n_{a t}^{\beta-1}, \\
w_{t} & =(1-\alpha-\beta) A_{t} k_{a t}^{\alpha} n_{a t}^{\beta}=p_{t}(1-\theta-\gamma) B_{t} k_{m t}^{\theta} z_{m t}^{\gamma}, \\
1 & =p_{t} \gamma B_{t} k_{m t}^{\theta} z_{m t}^{\gamma-1} .
\end{aligned}
$$

Of course, these equalities will hold only for the technologies that are used in equilibrium. The following proposition establishes the firms that will open in equilibrium. ${ }^{3}$

Proposition 1 Domestic firms will enter the market of non-primary goods if

$$
p_{t}>\frac{A^{1-\gamma}}{\gamma^{\gamma} B}\left(\frac{\alpha}{\theta}\right)^{\theta}\left(\frac{1-\alpha-\beta}{1-\theta-\gamma}\right)^{1-\theta-\gamma} n^{\beta(1-\gamma)} k_{t}^{\alpha(1-\gamma)-\theta} .
$$

Primary goods will always be produced if $N>0$.

The right side of expression (15) determines a minimum price above which it becomes profitable for the producers of non-primary products to enter the market. This minimum

\footnotetext{
${ }^{3}$ The proofs of the propositions presented in the paper are in the mathematical appendix.
} 
price depends on the relative natural endowment, the stock of capital per capita, the sector productivities and the factor intensities. Let us denote it by $p^{\min }\left(k_{t} ; n, A_{t}, B_{t}\right)$. A small open economy then specializes in $a$-products if $p^{\min }\left(k_{t} ; n, A_{t}, B_{t}\right)$ is greater than or equal to the international price $p_{t}$. More specifically, closing the non-primary sector becomes more appealing as $n$ increases and as $p_{t}$ declines or, in other words, as the primary-goods activity becomes relatively more productive for given $k_{t}$. In addition, if this activity is more capital intensive than the non-primary one, larger values of $k_{t}$ have the same effect on the minimum price as larger stocks of $n_{t}$. It is easy to show that under diversified production, the function $p^{\text {min }}$ evaluated at $k_{t}=k_{a t}$ and $n=n_{a t}$ must equal the international price level $p_{t}$ at every point in time $t$ for the market-equilibrium zero-profit condition to be satisfied, a property that will prove helpful in our analysis.

From the firms' optimality conditions, we can derive expressions for input intensities in each sector under diversified production. Let us define the relative factor price $\omega_{k t}=w_{t} / r_{k t}$. The efficiency conditions in production (11) and (13) determine the optimal allocations of capital as a function of this relative factor price:

$$
\begin{aligned}
k_{m t} & =\left(\frac{\theta}{1-\theta-\gamma}\right) \omega_{k t}, \\
k_{a t} & =\left(\frac{\alpha}{1-\alpha-\beta}\right) \omega_{k t} .
\end{aligned}
$$

It follows from (16) and (17) that primary goods will be more capital-labor intensive if and only if $\theta(1-\beta)<\alpha(1-\gamma)$. Similarly, defining the relative factor price $\omega_{n t}=w_{t} / r_{n t},(12)$, (13) and (14) yield that

$$
\begin{aligned}
& n_{a t}=\left(\frac{\beta}{1-\alpha-\beta}\right) \omega_{n t}, \\
& z_{m t}=\left(\frac{\gamma}{1-\theta-\gamma}\right) w_{t} .
\end{aligned}
$$

From equations (8), (9), (16) and (17), we can write

$$
k_{t}=k_{m t}\left[\left(1-l_{m t}\right) \frac{\alpha(1-\theta-\gamma)}{\theta(1-\alpha-\beta)}+l_{m t}\right] .
$$

It is also easy to relate $n_{a t}$ and $k_{a t}$. In particular, equation (11) implies that

$$
n_{a t}=\left[\frac{r_{k t}}{\alpha}\left(\frac{k_{a t}}{A_{t}}\right)^{1-\alpha}\right]^{1 / \beta}
$$

Another relevant variable is aggregate per capita output, defined as a weighted sum of final primary- and non-primary-goods production,

$$
y_{t}=l_{a t} y_{a t}+(1-\gamma) p_{t} l_{m t} y_{m t},
$$


where the last term is gross value added in the non-primary sector. Therefore, using the optimality conditions (11), (16), (17) and (8), we can write a country's GDP per capita under diversified production equilibrium as

$$
y_{t}=A_{t} k_{a t}^{\alpha} n_{a t}^{\beta}\left[1+l_{m t} \frac{\theta-(1-\gamma)(\alpha+\beta)}{1-\theta-\gamma}\right]
$$

As a consequence, the economy's GDP increases with larger allocations of labor to the production of primary goods if and only if this activity is less labor intensive than gross value added in the non-primary sector. ${ }^{4}$

Before finishing this section, let us briefly describe the steady-state equilibrium path. Over this equilibrium path, the employment of the natural input, the labor shares and the rental price of capital will remain invariant, and the rest of variables will grow at constant rates (see appendix for details). Let an asterisk $(*)$ denote steady-state outcomes, then the consumers' optimality condition (5) implies

$$
\frac{r_{k t}^{*}}{p_{t}^{*}}=G_{k}^{*} \rho^{-1}+\delta-1
$$

where $G_{i}$ represents the gross rate of growth of variable $i$. Here we have used the result that $G_{c}^{*} / G_{p}^{*}=G_{k}^{*}$. In addition, the growth rate of output per capita and the growth rate of the price level are functions of the growth rates of productivity parameters in each sector:

$$
G_{y}^{*}=\left(G_{A}^{1-\theta} G_{B}^{\alpha}\right)^{\frac{1}{1-\theta-\alpha \gamma}}
$$

and

$$
G_{p}^{*}=\left(\frac{G_{A}^{1-\theta-\gamma}}{G_{B}^{1-\alpha}}\right)^{\frac{1}{1-\theta-\alpha \gamma}}
$$

\section{The Developing Small-Open Economy}

Suppose that we split our set of small open economies into two groups. The big one, which we call the developed world, is composed of all but one of the countries; all economies within this group are identical in all aspects and have already reached the steady-state. The second group is composed of the remaining economy, which we call developing or late-blooming economy because it possesses a capital stock below its steady-state value, and below the steady-state value of the developed world. The equilibrium relative price of goods will be pinned down by

\footnotetext{
${ }^{4}$ The definitions of aggregate output and aggregate consumption in expressions (5) and (22), respectively, are in current prices. As Kehoe and Ruhl (2008) show, when comparing aggregate variables across countries and time, one should use constant prices and the output or expenditure approach. Notice that definition (22) employs the output approach. In addition, the difference between current and constant prices is not important in our simulations because the international output price remains constant.
} 
the steady state in which the big group is located, and then $p_{t}=p_{t}^{*}$ for all $t$. A full description of the behavior of the developed world, including the determination of $p_{t}^{*}$, is provided in the appendix. In what follows we concentrate on the developing economy.

The developing economy will take $p_{t}^{*}$ as given. Substituting $p_{t}=p_{t}^{*}$ in equations (2) to (13), we obtain the equation system that characterizes the dynamics of this economy. It can be easily shown that this late-blooming economy will accumulate capital until its rental rate falls down to the world's rate $r_{k t}^{*}$, which is exclusively determined by consumers' preferences and $p_{t}^{*}$ (see equation $(24)$ ), and that its pattern of production along the adjustment path will follow from Proposition 1.

Evaluating the impact of the natural input on growth along the transitional process requires the use of numerical methods; the next section carries out this numerical exercise. Here, we focus on the steady-state scenario, which can be studied analytically. ${ }^{5}$ From now on, the asterisk $(*)$ denotes the world economy's diversified-production equilibrium, which is not affected by the behavior of the (still developing) small-open economy. In turn, the superscript $\left({ }^{s s}\right)$ denotes steady-state values for the developing economy.

Expression (15) determines the threshold level of the capital stock that defines the small economy's diversification interval for given $p_{t}^{*}, n$ and the sectoral efficiency levels. Consider first the case that the late-bloomer ends its development path diversifying production. Given that consumers' preferences dictate that $r_{k t}^{s s}=r_{k t}^{*}$, equations (11) to (13), (21) and (24) imply that the long-run capital-labor ratio in the non-primary sector will equal that of the world economy, $k_{m t}^{s s}=k_{m t}^{*}$. This is all we need to guarantee that the same will hold in the primary sector, $k_{a t}^{s s}=k_{a t}^{*}$, that factor-price equalization holds in the long-run $\left(w_{t}^{s s}=w_{t}^{*}\right.$ and $r_{n t}^{s s}=r_{n t}^{*}$ for $i=a, m)$, and that the small open economy will be using the same $N$-labor and $Z$-labor ratios as the rest of the world (i.e., $n_{a t}^{s s}=n_{a t}^{*}$ and $z_{m t}^{s s}=z_{m t}^{*}$ ).

In the long-run, given natural input endowments, the difference between the small open economy and the world economy will be in the labor allocations and in the overall capital stocks. The stock of capital per worker $k_{t}^{s s}$ will increase with $n$ if primary goods are more capital intensive; it will fall with $n_{t}$ otherwise. To see this, notice that at the steady state $k_{t}^{s s}=l_{a}^{s s} k_{a t}^{*}+\left(1-l_{a}^{s s}\right) k_{m t}^{*}$, and that $k_{a t}^{*}$ and $k_{m t}^{*}$ are exogenous constants to the small open economy and do not depend on its natural input endowment.

As a result, the effect of an increase in the natural resource on the long-run income can be positive or negative. From the economy's demand side, income per worker can be written

\footnotetext{
${ }^{5}$ Atkeson and Kehoe (2000) show that, in the standard dynamic Heckscher-Ohlin model, a country that starts developing later than the world economy remains permanently poorer. Guillo and Perez-Sebastian (2013), however, prove that this is not the case when inputs in fixed supply are present.
} 
as $y_{t}^{s s}=w_{t}^{*}+r_{k t}^{*} k_{t}^{s s}+r_{n t}^{*} n$. In this expression, natural input rents always rise with $n .^{6}$ Arguments above, however, imply that the steady-state capital stock $k_{t}^{s s}$ can go up or down as $n$ rises. Whether $y_{t}^{s s}$ increases with the natural input will ultimately depend on the inputs' shares in the same way as in expression (23).

From the economy's production side, the forces that lead to this finding are the following. On the one hand, more natural riches increase the productivity of all inputs; this is good for income. On the other, the increase in the fixed factor reallocates capital and labor from the rest of the economy to the sector that employes $N$. In a small-open economy for which the world's relative price is given, the latter Rybczynski effect implied by the augmented factor can reverse the positive productivity effect, and generate a lower long-run per capita income when primary goods are less capital intensive.

Consider now the scenario of long-run specialization, which has also interesting implications. Proposition 1 implies that specialization in primary goods will occur in the long run whenever $n \geq n_{a t}^{*}$. In that case, income per capita is given by $y_{t}^{s s}=A_{t}\left(k_{t}^{s s}\right)^{\alpha} n^{\beta}$, with $k_{t}^{s s}=k_{a t}^{*}\left(n / n_{a t}^{*}\right)^{\beta /(1-\alpha)}$, expression that follows from the equalization of interest rates, $r_{k t}^{s s}=r_{k t}^{*}$. Therefore, income increases with the natural endowment. Moreover, long-run income can be above the world's average if $n$ is sufficiently large.

The next proposition summarizes these results.

Proposition 2 Suppose a small open economy that starts its adjustment path with a capitallabor endowment $k_{0}<\min \left\{k_{a}^{*}, k_{m}^{*}\right\}$ and a stock of the natural resource $N$. (a) At the steady state, it will diversify production if $n<n_{a t}^{*}$; it will specialize in the production of a-goods otherwise. (b) Under diversification, factor price equalization will hold, and the country's income $y_{t}^{\text {ss }}$ will decrease (increase) with $n$ if $\alpha+\beta<(>) \theta /(1-\gamma)$, $y_{t}^{s s}$ will not depend on $n$ if labor shares in value added across sectors are the same. (c) Under specialization, $y_{t}^{s s}$ always rises with $n$.

A final remark: findings in this section depend mainly on the small economy assumption, the country's initial capital stock and openness are secondary driving forces. If economies were open but not small, the steady-state relative price of non-primary goods would be positively related to the natural endowments of the different countries. As a result, the relation between a country's natural endowment and its long-run income could be always positive, even in the diversification cone, provided that the country is relatively large. On the other hand, it is straightforward that the steady state results would apply to any small-open economy that

\footnotetext{
${ }^{6}$ Balanced trade implies that saving is equal to gross investment at every period, so the relationship between saving and the natural endowment at the steady state is the same as the one between the capital stock and $n$.
} 
belongs to the developed world if we consider different $N$-labor ratios across countries within that group.

\section{Quantitative outcomes}

Next we conduct numerical experiments to learn more about the impact of a country's relative natural endowment on its steady-state level of per capita output, its speed of convergence, and how these effects translate into the so called curse of natural resources.

We first calibrate the model parameters - a summary is included in Table 1. Second, we compute the steady-state outcomes of a small open economy and its asymptotic speed of convergence for different values of $n$ comparing the convergence rates implied by the model with those in the empirical literature. Finally, we use the linearized dynamic system to obtain estimates of the resource curse implied by the model and compare them to the resource curse found in the data, focusing on the U.S. states case. A complete description of the normalized system is given in the appendix.

\subsection{Calibration}

The first issue is choosing an appropriate measure of $N$. We focus on main natural resources, namely land, coal, natural gas and oil. The sectors that employ those inputs directly agriculture, and the coal, natural gas and oil extraction activities - account altogether for 94 percent of the US primary sector's total value added.

Let us start the calibration with the production function parameters. The main source of the parametrization is Herrendof and Valentinyi (2008). Because these authors build their estimates on 1997 U.S. input-output tables, we use these statistics whenever possible. The parameter $\beta$ can be obtained as the sum of the land and other resource rents shares of the primary-sector's value added. The land income share of Agriculture according to Herrendof and Valentinyi (2008) is 0.11 in purchaser prices. In turn, according to the World Development Indicators, the share of rents from oil, natural gas and coal in GDP is, on average, 0.0046 over the period 1995-1999. Moreover, the 35-KLEMS input-output data base constructed by Jorgenson and Stiroh (2000) provides GDP shares of the primary (agriculture+oil+gas+coal) and agricultural sectors of 0.0367 and 0.0225, respectively. Employing those numbers, we can compute the natural-resource share in the primary sector as:

$$
\beta=\frac{0.11 Y_{a g r}+0.0046 * G D P}{Y_{\text {agr }}+Y_{C G O}}=\frac{(0.11)(0.0225)+0.0046}{0.0367}=0.1931
$$

where $Y_{a g r}$ and $Y_{C G O}$ are output from agriculture and from coal, gas and oil extraction, respectively. 
Table 1: Calibrated parameters and targets

\begin{tabular}{ccc}
\hline \hline Parameter & $\begin{array}{c}\text { Benchmark } \\
\text { value }\end{array}$ & Target $^{\dagger}$ \\
\hline$\alpha$ & 0.3479 & Total-capital share in primary sector $(\alpha+\beta)$ \\
$\beta$ & 0.1931 & Income share of land, oil, coal, and natural gas rents \\
$\theta$ & 0.2584 & Economy-wide reproducible-capital share $\left(s_{a} \alpha+\left(1-s_{a}\right) \frac{\theta}{1-\gamma}\right)^{\ddagger}$ \\
$\gamma$ & 0.0509 & Primary goods employed per unit of non-primary products \\
$G_{y}$ & 0.02 & Postwar average growth rate of U.S. per capita real GDP \\
$\rho$ & 0.98 & Postwar average U.S. investment share $(21 \%)$ \\
$\delta$ & 0.05 & Standard in literature \\
$\varphi$ & 0.0069 & Primary consumption goods share of GDP $(0.5279 \%)$ \\
$n$ & state specific & Primary sector's GSP share in 1986 \\
\hline \hline
\end{tabular}

${ }^{\dagger}$ If not stated otherwise, the source of the data is the 1997 U.S. input-output tables.

${ }^{\ddagger} s_{a}$ is the GDP share of agriculture and the oil, gas and coal extraction industries $(3.67 \%)$.

Herrendof and Valentinyi (2008) estimate that the land and capital shares of U.S. GDP are 0.05 , and 0.33 , respectively. If we subtract from the latter figure the share of natural resource rents in GDP (0.0046), we are left with a reproducible capital share of about 0.275 for the whole economy. Since the parameter $\alpha$ and the ratio $\theta /(1-\gamma)$ represent the capital shares of sectoral value added, we can write that

$$
0.0367 \alpha+(1-0.0367) \frac{\theta}{1-\gamma}=0.275
$$

In the last expression, the parameter $\gamma$ is the share of intermediate goods from the primary sector employed in the production of non-primary goods. According to the 1997 input-output tables, the amount of intermediate goods generated by the primary sector represents 5.09 percent of total non-primary commodity output. Then, we pick $\gamma=0.0509$.

In addition, the 35-KLEMS input-output database implies that the capital share of value added in our natural resource sector is 0.541 in 1997. Substracting the calibrated value of $\beta$, we are left with a reproducible capital share of 0.3479 in the primary sector, that is $\alpha$. We can now solve (28) for $\theta$, which delivers $\theta$ equal to 0.2584 .

The above parameter values represent the benchmark calibration of input shares. This calibration implies that the primary sector is more capital intensive than the non-primary sector. Alternative (reasonable) values for $\beta$ and $\gamma$ do not change the qualitative results of the model and so they are not reported, although smaller values of $\beta$ improve slightly the model's quantitative performance. To check robustness, however, we do consider different values of the capital shares; in particular,

$$
(\alpha, \theta)=\{(0.4,0.256),(0.348,0.258),(0.275,0.261),(0.2,0.264),(0.1,0.267)\} .
$$


The second element of the set, $(\alpha, \theta)=(0.348,0.258)$, is the benchmark case. The rest of pairs in (29) follow from (28) for different values of $\alpha$. The last three bundles imply that the non-primary sector is more capital intensive than the primary sector, that is, they represent the opposite to what the data suggest. Note also that for the third element of the set, $(0.275,0.261)$, the capital shares of sectoral value added are the same as the aggregate capital share. We include them to illustrate how the results crucially depend upon the difference between the values of $\alpha$ and $\theta /(1-\gamma)$.

The PWT 8.0 provide an average growth rate of per capita real GDP for the U.S. equal to 2 percent from 1950 to 2007 . This implies that $G_{y}=G_{k}=1.02$ assuming that the relative price of non-primaries is constant along the balanced-growth path. The depreciation rate of capital $\delta$ is set to 0.05 . In this case, according to (43) in the appendix, 96.4 percent of the labor force will be employed in the non-primary sector at the steady state equilibrium $\left(l_{m}^{*}=0.964\right)$ independently of the natural resource endowment of the world economy, $n^{*}$. Given that, we assume $n^{*}=1$. The implied relative price according to (45) is then $p^{*}=2$ if initial efficiency levels are the same in both sectors, $A_{0}=B_{0}$.

We still have to give values to the utility function parameters. The same year interval in the PWT 8.0 gives an average investment share equal to 21 percent. Then, we can write that $\left(G_{k}+\delta-1\right) p_{t}^{*} k_{t}^{*} / y_{t}^{*}=0.21$. This equation and the assumption that the aggregate capital income share, $r_{k}^{*} k_{t}^{*} / y_{t}^{*}$, is 0.275 imply that the real interest rate at the steady state, $r_{k}^{*} / p^{*}$, equals 0.091. Then, equation (24) implies a value for the discount rate $\rho$ of 0.98 .

With respect to the weight of primary-products in consumption, $\varphi$, we proceed as follows. Since the investment share is 0.21 , we have that at the steady-state

$$
\frac{p_{t}^{*} y_{m t}^{*} l_{m t}^{*}-p_{t}^{*} c_{m_{t}}^{*}}{y_{t}^{*}}=0.21
$$

Using expression (4) and the fact that 0.5279 percent is the households' primary-goods consumption share of GDP minus government spending, we can rewrite the last expression as

$$
\frac{p_{t}^{*} y_{m t}^{*} l_{m t}^{*}}{y_{t}^{*}}-\left(\frac{1-\varphi}{\varphi}\right) \frac{c_{a t}^{*}}{y_{t}^{*}}=(1-0.0367)-\left(\frac{1-\varphi}{\varphi}\right) 0.005279=0.21
$$

This assigns a value of 0.006959 to $\varphi$. Finally, for each of the 49 states in the U.S. sample used by Papyrakis and Gerlagh (2007), we solve for the value of $n$ that makes the primary sector's GDP share of the small open economy equal to the resource endowment measure used by these authors (the primary sector's Gross State Product in 1986). This implies a minimum value of $n$ equal to 0.114 (which corresponds to New Jersey) and a maximum value of $n$ equal to 5.311 (which corresponds to Wyoming). The benchmark scenario of the model yields a diversified production interval of the natural endowment equal to $(0,27.71)$. 
Table 2: Steady-state output relative to the world's average for different land endowments and capital shares

\begin{tabular}{|c|c|c|c|c|c|c|}
\hline \multirow{3}{*}{\multicolumn{2}{|c|}{$\begin{array}{l}\text { Technology parameters } \\
\beta=0.193, \gamma=0.0509\end{array}$}} & \multicolumn{5}{|c|}{ Steady state relative income } \\
\hline & & \multicolumn{5}{|c|}{ Natural resource endowment $^{\dagger}, n$} \\
\hline & & \multirow{2}{*}{$\begin{array}{c}0.1 \\
0.999\end{array}$} & \multirow{2}{*}{$\begin{array}{c}0.5 \\
0.999\end{array}$} & \multirow{2}{*}{$\begin{array}{l}1 \\
1\end{array}$} & \multirow{2}{*}{$\begin{array}{c}3 \\
1.001\end{array}$} & \multirow{2}{*}{$\begin{array}{c}5 \\
1.003\end{array}$} \\
\hline$\alpha=0.1$ & $\theta=0.267$ & & & & & \\
\hline$\alpha=0.2$ & $\theta=0.264$ & 0.991 & 0.995 & 1 & 1.017 & 1.035 \\
\hline$\alpha=0.275$ & $\theta=0.261$ & 0.986 & 0.992 & 1 & 1.029 & 1.059 \\
\hline$\alpha=0.348$ & $\theta=0.258$ & 0.981 & 0.989 & 1 & 1.041 & 1.082 \\
\hline$\alpha=0.4$ & $\theta=0.256$ & 0.977 & 0.987 & 1 & 1.049 & 1.099 \\
\hline \multicolumn{7}{|c|}{ Special cases, Figure 2} \\
\hline$\alpha=0.1$ & $\theta=0.3$ & 1.001 & 1.000 & 1 & 0.996 & 0.992 \\
\hline$\alpha=0.275$ & $\theta=0.444$ & 1 & 1 & 1 & 1 & 1 \\
\hline
\end{tabular}

\subsection{Long-run output}

Let us recall expression (23): under diversified production, steady-state output in the smallopen economy can grow, fall or remain constant for different values of the natural resource, depending on whether the primary sector is less, more, or equally labor intensive than the non-primary activity, respectively. Figure 2 illustrates this behavior. The Figure depicts the small open economy's long-run output (LHS panels) and consumption (RHS panels) relative to the corresponding developed world averages against the relative natural resource endowment. The three cases shown are for illustrative purposes only, and do not correspond necessarily to those in (29).

In the charts, the vertical dotted line represents the $n_{a}^{*}$ level above which the economy will specialize in the production of primary goods. Within the diversified production interval, relative income, $y / y^{*}$, is a linear function of the natural resource endowment because factor price equalization holds and $l_{a}=n / n_{a}^{*}$. In the top-left panel of Figure 2, the production of primary goods is less labor intensive than the production of non-primary goods and so $y / y^{*}$ rises with the natural resource endowment. In the middle-left panel, $y / y^{*}$ remains constant inside the diversification interval because gross value added is equally labor intensive in both sectors. Finally, in the bottom-left chart, $y / y^{*}$ falls with the natural endowment to the left of $n_{a}^{*}$ because the primary sector is more labor intensive. Outside the diversification zone, the small open economy's output equals $A_{t} n^{\beta} k_{t}^{\alpha}$, and so the relative output curve is increasing 
Figure 2: Long-run output and consumption relative to the developed-world average as a function of the natural stock
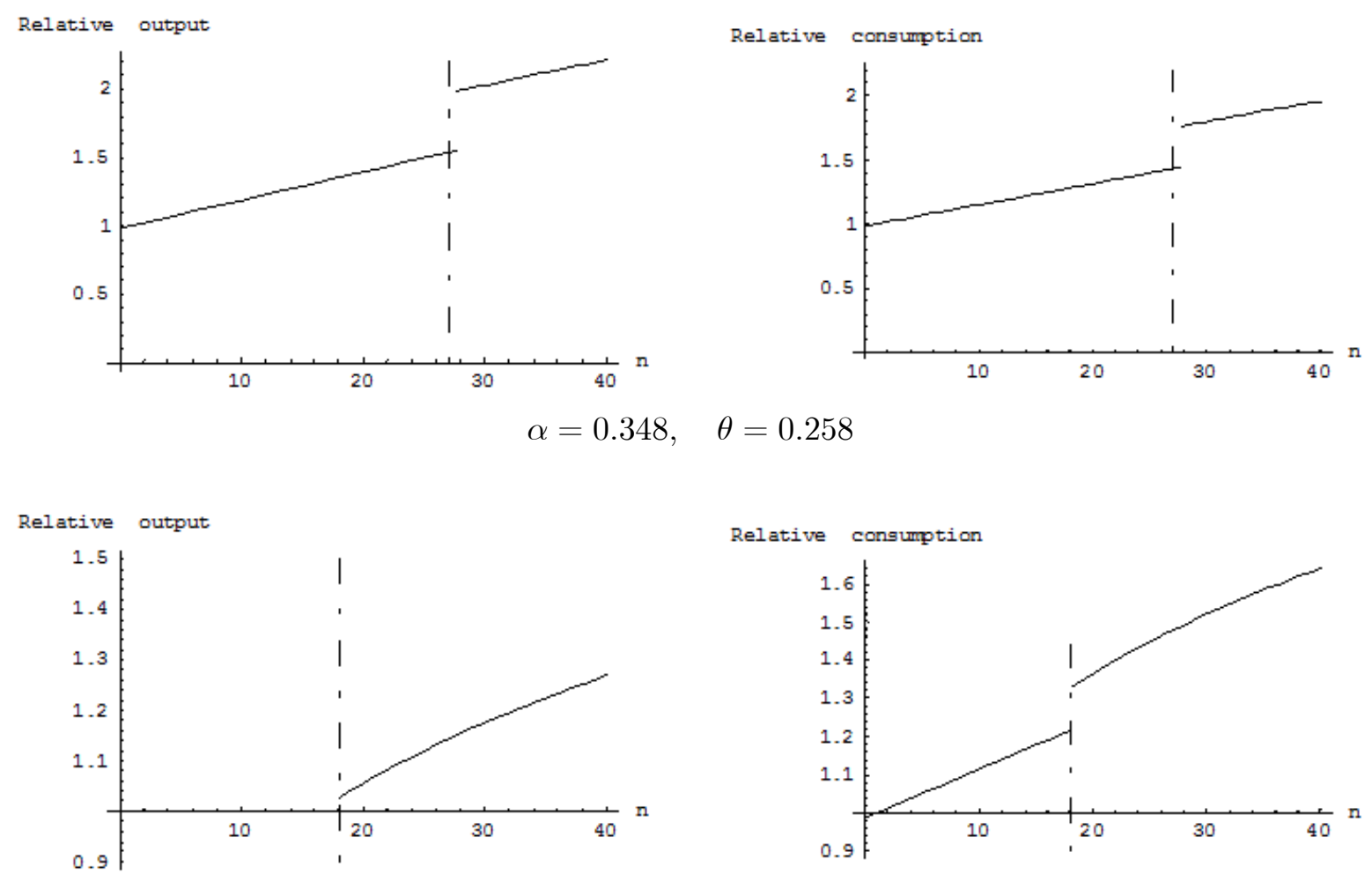

$$
\alpha=0.275, \quad \theta=(1-\gamma)(\alpha+\beta)=0.444
$$
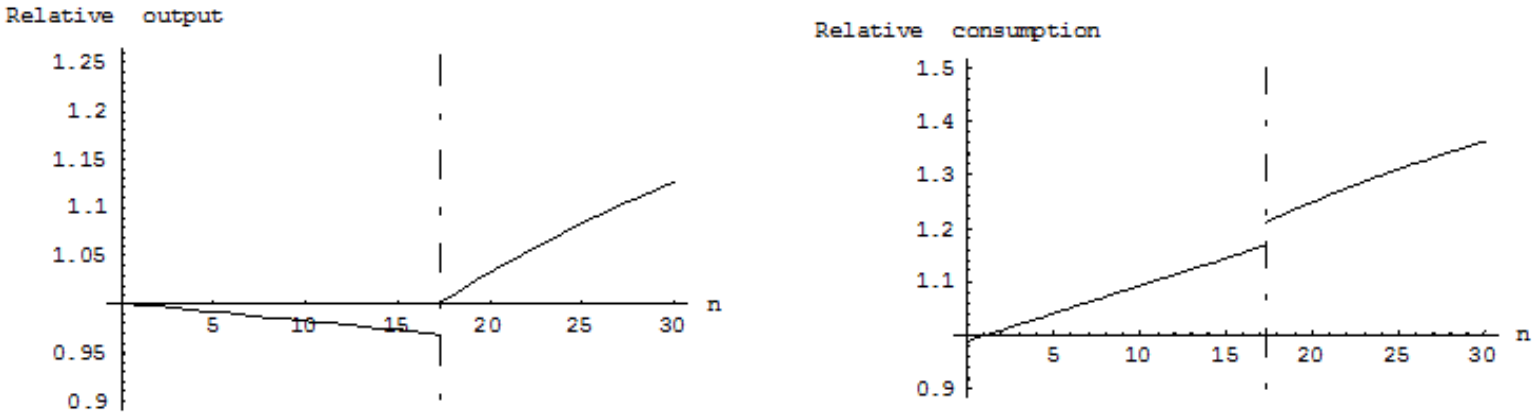

$$
\alpha=0.1, \quad \theta=0.3
$$


and concave in $n$.

To get an idea of the predicted differences, Table 2 shows the values of $y / y^{*}$ for different levels of $n$ and for the different values of the capital shares reported in (29). More specifically, each column shows how the steady state relative output changes as we increase the primary sector's capital share from $\alpha=0.1$ to $\alpha=0.4$ for a given value of $n$, in each of these cases the capital share of the non-primary sector, $\theta$, is such that condition (28) is satisfied. Note that in all the cases reported in Table 2 the primary sector is less labor intensive than the non-primary sector, except for the last two rows that correspond to the special cases in Figure 2 explained above.

We see that steady-state income differences among economies that have different natural resource endowments are sizable, and that these differences increase with the capital share in the sector that uses the natural input more intensively. For example, for $(\alpha, \theta)=(0.1,0.267)$, first row in Table 2, income per capita is 1.001/0.999 $=1.002$ times larger in an economy with $n=3$ than in an economy with $n=0.1$. This difference rises and generates a 1.049/0.977= 1.074 fold when $(\alpha, \theta)=(0.4,0.256)$; the ratio equals 1.061 in the benchmark case.

Figure 2 also shows an interesting feature of the model: steady-state consumption (RHS panels) always rises with the natural input. So larger amounts of the natural endowment imply higher long-run welfare even if income levels are smaller. The reason is that larger amounts of $n$ imply lower capital levels when the primary sector is less capital intensive than non-agriculture, which lowers steady-state saving and investment. This effect of the natural resource on investment is stronger than the effect on income (which depends ultimately on labor intensities) and as a result steady-state consumption rises. In contrast, when the primary sector is more capital intensive, both income and investment rise with $n$, but the effect of $n$ on income is stronger, so steady state consumption also rises. A consequence of all these movements is that the consumption share of income falls when $\alpha \geq 0.275$ and rises when $\alpha<0.275$.

\subsection{The asymptotic speed of convergence}

In this section we compute the small economy's asymptotic speed of convergence. ${ }^{7}$ Table 3 reports the results for different values of $n$ within the diversified production interval for the pairs of sectoral capital shares given in (29). Outside the diversified production interval, the convergence speed does not depend on $n$. This follows from the fact that the convergence rate depends on the natural endowment only if, along the adjustment path, the economy transfers resources between the two sectors that have a different capital share. As a consequence, the

\footnotetext{
${ }^{7}$ See the appendix for details. The program was written in Mathematica and is available from the authors upon request.
} 
Table 3: Speeds of convergence for different parameterizations, percentage

\begin{tabular}{|c|c|c|c|c|c|c|}
\hline \multirow{3}{*}{\multicolumn{2}{|c|}{$\begin{array}{c}\text { Technology parameters } \\
\beta=0.193, \gamma=0.0509\end{array}$}} & \multirow{2}{*}{\multicolumn{5}{|c|}{$\begin{array}{c}\text { Speeds of convergence } \\
\text { Natural resource endowment }{ }^{\dagger}, n\end{array}$}} \\
\hline & & & & & & \\
\hline & & \multirow{2}{*}{$\begin{array}{l}0.1 \\
9.85\end{array}$} & \multirow{2}{*}{$\begin{array}{l}0.5 \\
9.88\end{array}$} & \multirow{2}{*}{$\begin{array}{c}1 \\
9.93\end{array}$} & \multirow{2}{*}{$\frac{3}{10.09}$} & \multirow{2}{*}{$\frac{5}{10.26}$} \\
\hline$\alpha=0.1$ & $\theta=0.267$ & & & & & \\
\hline$\alpha=0.2$ & $\theta=0.264$ & 10.01 & 10.06 & 10.12 & 10.34 & 10.57 \\
\hline$\alpha=0.275$ & $\theta=0.261$ & 10.09 & 10.09 & 10.09 & 10.09 & 10.09 \\
\hline$\alpha=0.348$ & $\theta=0.258$ & 10.19 & 10.1 & 9.99 & 9.6 & 9.26 \\
\hline$\alpha=0.4$ & $\theta=0.256$ & 10.25 & 10.07 & 9.86 & 9.13 & 8.55 \\
\hline
\end{tabular}

convergence speed is independent of $n$ in a specialized economy. This is also the reason behind the constant speed of convergence in the third row of Table 3 . When $\alpha=\theta /(1-\gamma)=0.275$, sectoral capital shares of value added do not differ and then the speed of converge does not change with $n$.

Other interesting results are the following. Most predicted values are consistent with convergence rates estimated in the literature, which vary between the 0.4 percent reported by Barro and Sala-i-Martin (1995) and the 10 percent found by Caselli et al. (1996). Second, when $\alpha>0.275$ more $n$ generates a lower speed of convergence for given $\alpha$, and when $\alpha<0.275$ larger amounts of the natural input increase the speed of convergence. Third, relative differences in predicted numbers are significant and tend to rise as $\alpha$ moves away from the equal-shares case. For example, when $(\alpha, \theta)$ equals $(0.4,0.256)$, the largest speed, 10.25 , is more than 1.5 percentage points larger than the lowest, 8.55 ; this is a significant difference, bigger than the discrepancy when $(\alpha, \theta)$ is $(0.348,0.258)$.

Let us give some intuition behind these results. As the appendix shows, the sign of the effect of the natural endowment on the speed is the opposite to the sign of the response of $\partial r_{k t+1} / \partial k_{t}$ to changes in $n$. This response, in turn, depends on two main derivatives: $\partial^{2} r_{k t+1} / \delta k_{m t+1} \partial n$ and $\partial^{2} k_{m t+1} / \delta k_{t} \partial n$. The sign of the first one is the opposite of the sign of $\alpha-\theta /(1-\gamma)$, and represents a capital share effect. More specifically, we know that as the share of capital becomes larger, the return to capital accumulation, that is, the interest rate, falls more slowly along the adjustment path, thus making the speed smaller. In our model, there are two sectors that employ capital. Hence, the de facto economy-wide capital share (EWCS) will be affected by the allocation of resources between them: we can write $E W C S=(\alpha-\theta /(1-\gamma)) s_{a}+\theta /(1-\gamma)$; where $s_{a}$ represents the primary sector's share of GDP. The primary activity has a larger natural input intensity. Hence, $s_{a}$ will tend to 
rise with $n$. As a consequence, the EWCS rises (falls) and the speed falls (rises) with $n$ if $\alpha>\theta /(1-\gamma)(\alpha<\theta /(1-\gamma))$; both remain constant if $\alpha=\theta /(1-\gamma)$.

The sign of the derivative $\partial^{2} k_{m t+1} / \delta k_{t} \partial n$ is also the opposite of the sign of $\alpha-\theta /(1-\gamma)$, and represents a capital accumulation effect. The accumulation of capital in the non-primary sector occurs more slowly (rapidly) as the natural endowment rises when the primary (nonprimary) sector is more capital intensive. The accumulation effect then goes in the same direction as the capital share effect described above. As a consequence, the effect of $n$ on the speed is negative if $\alpha>\theta /(1-\gamma)$, and positive if $\alpha<\theta /(1-\gamma)$.

Finally, it is worth noting that the dynamic system of the small developing economy described by equations (54) and (56) in the appendix could also be used to study the dynamics of a small early-bloomer economy that differed from the rest of the world only in its natural endowment and took the equilibrium sequence of world prices as given. Then, it follows that all the qualitative results obtained in this section apply to any small open economy regardless of its initial stock of capital.

\subsection{The natural resource curse}

The conclusion from the previous quantitative exercises is that natural inputs can have a significant impact on steady-state income and economic growth. The question that still needs to be answered is whether the identified new channel can generate a significant fraction of the observed natural resource curse. In this section, we address this issue employing the Papyrakis and Gerlagh (2007)'s sample that delivers a significant curse within 49 U.S. states (Delaware and District of Columbia were excluded because of some missing data) during the 14-year period 1986-2000. We choose this case because it is a more homogeneous group of economies, and less likely to be affected by mechanisms put forward by other theories. $\backslash$ caption $\{$ Initial relative income and growth rates across U.S. states $\backslash$ label $\{$ GeneralTest $\}$ \}

Papyrakis and Gerlagh use the primary sector's share of GSP in 1986 as the endowment measure of natural resources. The average endowment of the sample is 0.052. To have an idea of the curse, we can define resource rich and resource poor groups of states in different ways. For example, if we look at the 5 states at the top (Alaska, Louisiana, Oklahoma, South Dakota and Wyoming, with endowments above 0.11) and the 5 at the bottom (Connecticut, Massachusetts, New Hampshire, New Jersey and New York, with endowments below 0.009), they show average growth rates of 1.49 and 2.88 percent, respectively. Therefore, the ten percent richest states grew, on average, 1.39 percent points slower than the ten percent resource-poor. If, instead, we compare states below the first quartile and above the third quartile, we find a resource curse of 0.26 points. Finally, if we concentrate on the average 
growth rates of states below and above the mean, the growth gap is 0.23 percent.

We start by assessing the general capacity of the model to explain the curse. For that, we let each state have in 1986 a different relative-income distance to the balanced-growth path. This distance is computed assuming that long-run growth is $2 \%$ in line with our calibration. Each state has also a different endowment $n$ such that the primary sector share of GSP equals the endowment measure used by Papyrakis and Gerlagh. Armed with those starting values, 49 small-open economies - one for each U.S. state - are simulated over 14 periods using the linearized version of the equation system around the steady state, which allows calculating an average growth rate of $y$ for each state along the adjustment path.

Figure 3 presents the results. The LHS provides initial income levels relative to the longrun trend across states. Only nine states show income levels in 1986 above the long-run trend. We can also see that the state that is located further way, Alaska, is $50 \%$ above trend, which is more than twice the distance of any other state, and makes it look like an outlier. If Alaska is removed from the sample, the correlation between relative initial income and the natural endowment is merely 0.12 - compared to 0.44 when Alaska is included. The RHS chart in Figure 3, in turn, compares the average-growth predictions of the model to the data. It shows that the fit is surprisingly good, with a pseudo- $R^{2}$ of 0.96 . Model predictions across U.S. states with equal sectoral value-added capital shares SameKshare

Therefore, a combination of distance-to-balanced-growth-path and Rybczynski-type mechanisms do a very good job at explaining the curse found by Papyrakis and Gerlagh (2007). Our next task is assessing the contribution of the second of those channels to the negative effect of natural riches on economic growth for the proposed sample. With this aim, we repeat the previous experiment but shutting down the mechanism that operates through differences in sectoral capital shares. More specifically, we assume that the primary and non-primary sectors have the same capital weight in sectoral value added, that is, $\alpha=\theta /(1-\gamma)=0.275$, the case where the convergence speed is independent of $n$. The implied cloud of points is depicted in Figure 4. The fit is still good, but worse than before; now the pseudo- $R^{2}$ equals 0.85. The implication is that capital-share differences between sectors account for about $11 \%$ of the GSP-growth disparities in the sample.

The last exercise that we perform to dig deeper in the input-share effect is imposing a common distance to all states, and see what is the growth gap between the resource poor and resource rich states that the model is able to generate. To choose this common distance, we focus on economies located in 1986 below trend. These below-trend states provide an average income per capita in 1986 relative to its 2000 level equal to 0.685 . If we let this amount grow at the rate of the long-run trend $(2 \%)$ over 14 years, it becomes 0.90 . Therefore, assuming 
Figure 3: Initial relative income and growth rates across U.S. states
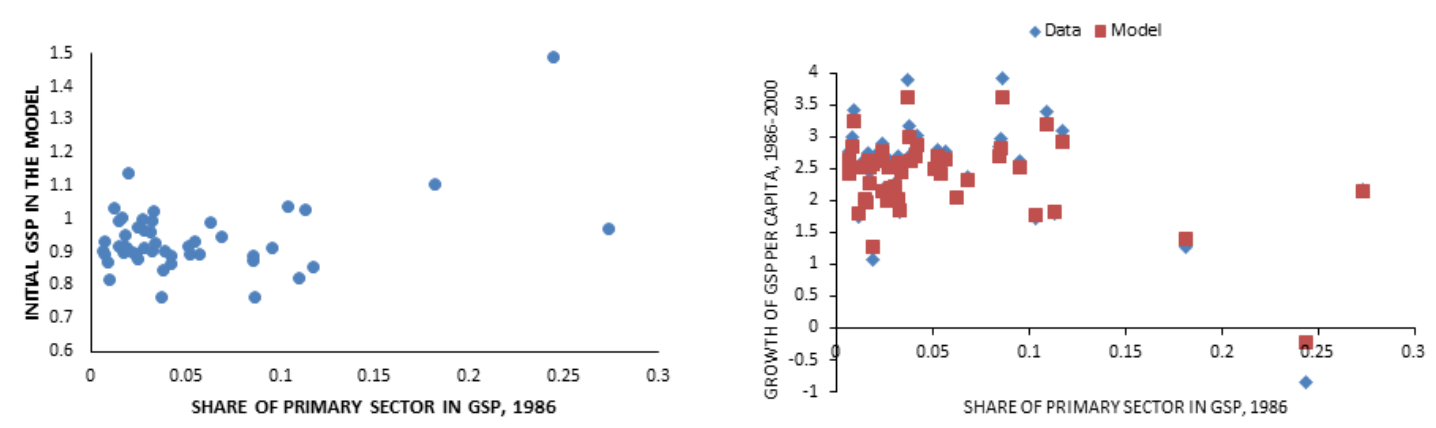

Figure 4: Model predictions across U.S. states with equal sectoral value-added capital shares

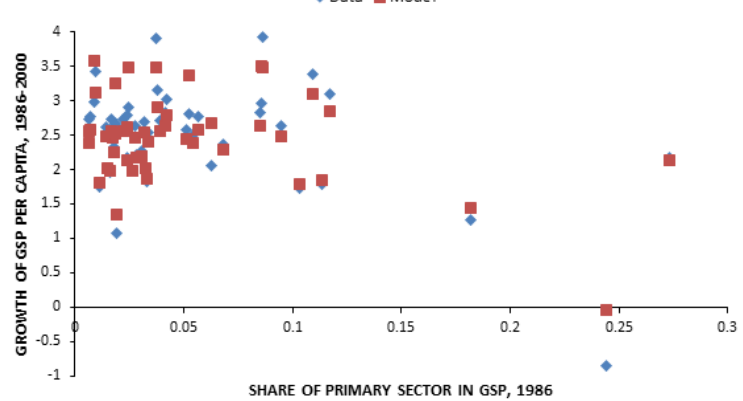


Table 4: Average growth gap between U.S. states,1986-2000, robustness analysis

\begin{tabular}{lcccc}
\hline \hline & $\begin{array}{c}\text { Natural } \\
\text { Resource abundance } \\
\text { Resource } \\
\text { criterion }\end{array}$ & \multicolumn{3}{c}{ Output growth (\%) } \\
\cline { 2 - 5 } & Data & Data & $\begin{array}{c}\text { States' specific distance } \\
\text { Model }\end{array}$ & $\begin{array}{c}\text { 10\% distance } \\
\text { Model }\end{array}$ \\
\cline { 2 - 5 } $10 \%$ poorest & & & & 2.75 \\
10\% richest & 0.007 & 2.88 & 2.07 & 2.646 \\
Growth gap & 0.171 & 2.08 & 0.68 & 2.634 \\
& & 0.80 & & 0.012 \\
NR below average & 0.024 & 2.55 & 2.467 & 2.645 \\
NR above average & 0.106 & 2.53 & 2.452 & 2.639 \\
Growth gap & & 0.02 & 0.015 & 0.006 \\
& & & & \\
\hline \hline
\end{tabular}

†Primary sector's share in GSP 1986, Papyrakis and Gerlagh (2007)'s sample excluding Alaska.

that all economies have reached the balanced-growth path by year 2000 , the 0.90 implies that the mean distance to the long-run trend in 1986 across states was 10 percent. Employing this common initial condition and the state-specific natural endowment, we obtain again the 14-year average growth rate of GDP per capita predicted by the model for the different economies. The only exception is Alaska that is excluded from the exercise because it is initially well above trend, showing a negative average growth rate of $-0.86 \%$, whereas all the other states provide growth rates above $1 \%$.

Table 4 shows the results: it includes the output growth rates given by the data, and the ones predicted by the model in two different scenarios: when economies start from their own specific distance to the long-run trend (fourth column), and when they start from the same distance (fifth column). The Table employs two different approaches to distinguish between the resource-rich and -poor. One compares the $10 \%$ poorest states to the $10 \%$ richest states; whereas the other one considers as natural resource scarce (abundant) states those whose natural endowment is below (above) average. We pay attention to the growth gap that the model is able to explain. We can see that this depends very much on the classification approach. The model does a good job in both cases: it can account for $0.015 / 0.02=75 \%$ of the growth gap between states below and above the mean; and 0.68/0.80 $=85 \%$ comparing the $10 \%$ poorest and $10 \%$ richest. Differences in input shares between sectors also have a sizable contribution of $0.006 / 0.02=30 \%$ to the gap when we compare states below and above average; however, this contribution becomes much smaller, 0.012/0.80 $=2 \%$, when we consider the 5 -top and the 5 states at the bottom. We conclude, then, that Heckscher- 
Ohlin forces are more important to explain observed growth disparities across states with intermediate stocks of natural resources.

\section{Conclusion}

Motivated by the empirical literature, this paper advances a new channel that can contribute to explain the puzzling natural resource curse result. The model is a standard dynamic Heckscher-Ohlin framework and delivers interesting results that occur in small-open economies that take international output prices as given and diversify production.

Within this framework, natural resources affect long-run income, but also growth through the convergence speed. Interestingly, these two effects can go in opposite directions and are quantitatively significant. They are driven by Rybczynski-type mechanisms as a consequence of the non-reproducible nature of natural resources and intersectoral differences in input shares. More specifically, a more capital-intensive primary activity implies that naturalresource abundant economies grow more slowly for a while along the adjustment process towards the steady state; however, they reach a higher long-run income if the labor share of primary output is smaller than the labor share of non-primary activities.

The quantitative exploration has shown that the model is indeed able to generate a natural resource curse. Furthermore, we have proved that the model is able to explain most of the per-capita GSP growth differences across U.S. states in the Papyrakis and Gerlagh (2007)'s sample. Distance to the long-run trend shows up as the main reason behind this result. Nevertheless, Rybczynski mechanisms can account for a significant part - equal to $11 \%$ percent - of these differences.

Besides providing a novel explanation for the resource-curse puzzle, our results also contribute to better understand the determinants of the speed of convergence. More standard economic growth frameworks such as Barro and Sala-i-Martin (1995) and Ventura (1997) imply that the convergence speed is only affected by deep parameters, like the consumptionsubstitution elasticity and the discount factor. Our work shows that some variables, like natural inputs, can also significantly affect it.

An implication of our analysis for empirical work is that estimated-coefficient signs in growth regressions for variables that can have transitional effects should be interpreted with caution: a negative (positive) coefficient does not necessarily mean that the variable has a negative (positive) effect on long-run income. Therefore, the resource-curse evidence provided by Sachs and Warner (2001), among others, may not imply that natural resources do not contribute positively to long-run income. Clearly, discriminating accurately between the longrun and transitional effects of these type of variables requires better empirical strategies. We 
leave this important issue to future research. 


\section{A The Model's Mathematical Appendix}

Proof of Proposition 1. Since the natural input is in (fixed) positive supply it is always profitable to produce a positive amount of primaries. By contradiction, suppose that the technology that requires the fixed factor is not used. Firms that have access to this technology will like to open if they expect making profits for the prices that prevail in the equilibrium where the economy is located.

In particular, given $N>0$, a firm chooses $K_{a t}$ and $L_{a t}$ to maximize profits that equal

$$
\Pi_{a t}=A_{t} K_{a t}^{\alpha} N^{\beta} L_{a t}^{1-\alpha-\beta}-r_{k t} K_{a t}-w_{t} L_{a t}-r_{n t} N .
$$

Using the first order conditions, the maximum level of profits per unit of the land then equals

$$
\frac{\Pi_{a t}}{N}=\beta A_{t}^{\frac{1}{\beta}}\left(\frac{1-\alpha-\beta}{w_{t}}\right)^{\frac{1-\alpha-\beta}{\beta}}\left(\frac{\alpha}{r_{k t}}\right)^{\frac{\alpha}{\beta}}-r_{n t} .
$$

In an equilibrium in which there is no production of primaries, it must be true that $r_{n t}=$ 0 . But then, in expression (32) maximum profits are strictly positive for all $t$, which is a contradiction.

Let us now look for the condition under which the non-primary sector will produce output. Suppose that only primaries are produced. If a firm jumps to manufacturing non-primaries, profits will equal

$$
\Pi_{m t}=p_{t} B_{t} K_{m t}^{\theta} Z_{t}^{\gamma} L_{m t}^{1-\theta-\gamma}-r_{k t} K_{m t}-Z_{t}-w_{t} L_{m t} .
$$

At the maximum, non-primary-production profits are

$$
\left(p_{t} B_{t}\right)^{\frac{1}{1-\theta-\gamma}}\left(\frac{\theta}{r_{k t}}\right)^{\frac{\theta}{1-\theta-\gamma}} \gamma^{\frac{\gamma}{1-\theta-\gamma}} B_{t} L_{m t}\left[1-\theta-\gamma-w_{t}\left(\frac{\left(\frac{r_{k}}{\theta}\right)^{\theta} \gamma^{-\gamma}}{p_{t} B_{t}}\right)^{\frac{1}{1-\theta-\gamma}}\right]
$$

The last expression will be positive if and only if

$$
p_{t} B_{t}>\left(\frac{w_{t}}{1-\theta-\gamma}\right)^{1-\theta-\gamma}\left(\frac{r_{k t}}{\theta}\right)^{\theta} \gamma^{-\gamma}
$$

Getting the equilibrium prices from the optimality conditions for primary products given in (11), (12) and (13), we obtain expression (15).

Proof of Proposition 2. (a) Let $D_{t}=A_{t}^{1-\gamma} / B_{t}$, which is the same for all countries, and let $p^{\min }\left(k_{t} ; n, D_{t}\right)$ represent the right side of expression (15). In the steady state

diversified production equilibrium, $p^{\min }\left(k_{a t}^{*} ; n_{a t}^{*}, D_{t}\right)=p_{t}^{*}, \underline{k}_{t}=k_{a t}^{*}\left(n_{a}^{*} / n\right)^{\frac{\beta(1-\gamma)}{\alpha(1-\gamma)-\theta}}$ solves $p^{\min }\left(k_{t} ; n, D_{t}\right)=p_{t}^{*}$ and so $\left(0, \underline{k}_{t}\right)$ and $\left(\underline{k}_{t}, \infty\right)$ are the diversification intervals in the cases $\alpha(1-\gamma)>\theta$ and $\alpha(1-\gamma)<\theta$, respectively. If $\alpha(1-\gamma)=\theta, p^{\min }\left(k_{t} ; n, D_{t}\right)$ does not depend on $k$.

(a.I) $\alpha(1-\gamma)>\theta$, so $k_{a t}>k_{m t} . \underline{k}_{t} \geq k_{a t}^{*} \Longleftrightarrow n_{a}^{*} / n \geq 1$. At the steady state, if the economy specializes in $a-$ goods, $r_{k t}^{s s}=r_{k t}^{*}$ and $l_{a}^{s s}=1$ would imply that $k_{t}^{s s}=$ 
$k_{a t}^{*}\left(n / n_{a}^{*}\right)^{\beta /(1-\alpha)}<k_{a t}^{*}$. So if $n_{a}^{*} / n>1$, then $k_{t}^{s s}<\underline{k}_{t}$ and so $l_{m}^{s s}>0$, hence $l_{a}^{s s}=1$ cannot be optimal. If $n_{a}^{*} / n \leq 1, k_{t}^{s s} \geq k_{a t}^{*}>\underline{k}_{t}$ and so $l_{a}^{s s}=1$ is optimal.

(a.II) $\alpha(1-\gamma)<\theta$, so $k_{a t} \lessgtr k_{m t}$. (i) Suppose $n_{a}^{*} / n>1$, and assume that $l_{a}^{s s}=1$, then $k_{t}^{s s}=k_{a_{t}}^{*}\left(n / n_{a}^{*}\right)^{\beta /(1-\alpha)}<\underline{k}_{t}$, but this inequality would be true if $\theta>1-\gamma$, which is false. So $l_{a}^{s s}=1$ cannot be optimal. (ii) Suppose $n_{a}^{*} / n \leq 1$, then $k_{a t}^{*} \leq \underline{k}_{t}$. Assume that $l_{a}^{s s}>0$ and $l_{m}^{s s}>0$, by (8) it must be true that $l_{a}^{s s}<1$. At the steady state (24) implies $r_{k t}=r_{k t}^{*}$, so (40) implies $k_{m t}^{s s}=k_{m t}^{*}$ since $p_{t}=p_{t}^{*}$. Moreover, $k_{m t}^{s s}=k_{m t}^{*}$ and $p_{t}=p_{t}^{*}$ imply $n / l_{a}^{s s}=n_{a}^{*}$ by (41), so $n<n_{a}^{*}$, which is a contradiction. Hence, $l_{a}^{s s}<1$ cannot be optimal.

(b) It follows from (a.ii) that in a diversified production equilibrium, $r_{k t}^{s s}=r_{k t}^{*}, k_{m t}^{s s}=k_{m t}^{*}$, $n_{a}^{s s}=n_{a}^{*}$, so $k_{a t}^{s s}=k_{a t}^{*}$ by (16) and (17). Then $r_{n t}^{s s}=r_{n t}^{*}$ and $w_{t}^{s s}=w_{t}^{*}$ by (12) and (13), respectively. So factor price equalization holds. In particular, the common capital-labor ratio at the non-primary sector in all small open economies as:

$$
k_{m t}^{s s}=\left[p_{t}^{*} \frac{B_{t}}{A_{t}}\left(\frac{\theta}{\alpha}\right)^{\alpha}\left(\frac{1-\theta-\gamma}{1-\alpha-\beta}\right)^{1-\alpha-\beta}\left(\frac{\gamma}{\beta}\right)^{\beta}\left(\frac{\theta}{G_{k} \rho^{-1}+\delta-1}\right)^{\frac{\beta-\gamma}{\gamma}}\right]^{\frac{\gamma}{(1-\theta) \beta-(1-\alpha) \gamma}} .
$$

(c) $l_{a}^{s s}=1$ implies that $k_{a t}^{s s}=k_{t}^{s s}$ and $n_{a}^{s s}=n$, then $y_{t}^{s s}=A_{t}\left(k_{t}^{s s}\right)^{\alpha} n^{\beta}$ by (6), which is always increasing in $n$.

The world economy Assume that all developed countries are at steady state and share the same endowments. So the equilibrium for the developed world economy will be the same as the equilibrium for a single large and closed economy, and it will not be affected by the behavior of the small (still developing) country. Then the world market clearing conditions for final goods are

$$
\begin{aligned}
c_{a t}+l_{m t} z_{m t} & =l_{a t} y_{a t}=A_{t} l_{a t} k_{a t}^{\alpha} n_{a t}^{\beta}, \\
c_{m t}+x_{t} & =l_{m t} y_{m t}=B_{t} l_{m t} k_{m t}^{\theta} z_{m t}^{\gamma}
\end{aligned}
$$

where $y_{i t}=Y_{i t} / L_{i t}$. In equilibrium, the world economy will produce positive amounts of both goods.

An expression for $x_{t}$ can be obtained using (36) and (37): $x_{t}=l_{m t} y_{m t}-c_{m t}=l_{m t} y_{m t}-$ $\left(\frac{c_{m t}}{c_{a t}}\right)\left(l_{a t} y_{a t}-l_{m t} z_{m t}\right)$. Then, (4), (16), (17) and the share of intermediate goods in $m$ production, given by

$$
\frac{z_{m t}}{p_{t} y_{m t}}=\gamma
$$

imply that

$$
x_{t}=\frac{r_{k t}}{p_{t}} \frac{k_{m t}}{\theta}\left[l_{m t}-\frac{1-\varphi}{\varphi}\left(\frac{1-\theta-\gamma}{1-\alpha-\beta} l_{a t}-\gamma l_{m t}\right)\right] .
$$

Conditions (11) and (38) imply that

$$
r_{k t}=\alpha A_{t} k_{a t}^{\alpha-1} n_{a t}^{\beta}=\theta\left(p_{t} \gamma^{\gamma} B_{t} k_{m t}^{\theta+\gamma-1}\right)^{\frac{1}{1-\gamma}} .
$$

Which along with (16) and (17) provide the price of non-primary goods as

$$
p_{t}=\left[\left(\frac{\alpha}{\theta}\right)^{\alpha}\left(\frac{1-\alpha-\beta}{1-\theta-\gamma}\right)^{1-\alpha}\left(\frac{n}{l_{a t}}\right)^{\beta} A_{t}\right]^{1-\gamma} \frac{\gamma^{-\gamma}}{B_{t} v} k_{m t}^{\alpha(1-\gamma)-\theta} .
$$


Condition (24) and equations (3) and (39) imply that, at the steady state

$$
k_{t}^{*}=k_{m t}^{*} \frac{G_{k}^{*} \rho^{-1}+\delta-1}{\left(G_{k}^{*}+\delta-1\right) \theta}\left[l_{m}^{*}-\frac{1-\varphi}{\varphi}\left(\frac{1-\theta-\gamma}{1-\alpha-\beta} l_{a t}^{*}-\gamma l_{m t}^{*}\right)\right],
$$

where $G_{k}^{*}$ is the gross growth rate of capital per capita along the balanced-growth path defined in the next section. Substituting (20) for $k_{t}^{*}$ in the last expression, $k_{m t}^{*}$ cancels out in both sides. Consequently, using (8), we find that $l_{m t}^{*}$, and so $l_{a t}^{*}=1-l_{m}^{*}$, does not depend on land:

$$
l_{m}^{*}=\frac{\frac{\alpha}{\theta} \frac{1-\theta-\gamma}{1-\alpha-\beta}\left[1+\left(\frac{1-\varphi}{\alpha \varphi}\right) \frac{G_{k}^{*} \rho^{-1}+\delta-1}{G_{k}^{*}+\delta-1}\right]}{\frac{G_{k}^{*} \rho^{-1}+\delta-1}{\theta\left(G_{k}^{*}+\delta-1\right)}\left(1+\gamma \frac{1-\varphi}{\varphi}\right)-1+\frac{\alpha}{\theta} \frac{1-\theta-\gamma}{1-\alpha-\beta}\left[1+\left(\frac{1-\varphi}{\alpha \varphi}\right) \frac{G_{k}^{*} \rho^{-1}+\delta-1}{G_{k}^{*}+\delta-1}\right]} .
$$

Notice as well that (42) then implies that the ratio $k_{t}^{*} / k_{m t}^{*}$ is also constant and independent of $n_{t}$.

Substituting (24) into (40) and using (41), we can solve for $k_{m t}^{*}$ :

$$
k_{m t}^{*}=\left\{\left[\left(\frac{\alpha}{\theta}\right)^{\alpha}\left(\frac{1-\alpha-\beta}{1-\theta-\gamma}\right)^{1-\alpha}\left(\frac{n}{l_{a t}^{*}}\right)^{\beta} \gamma A_{t}\right]^{\gamma} \frac{\theta B_{t}}{G_{k}^{*} \rho^{-1}+\delta-1}\right\}^{\frac{1}{1-\theta-\alpha \gamma}} .
$$

Finally, the last expression and (41) provide the following price level at steady state:

$p_{t}^{*}=\left\{\left[\left(\frac{\alpha}{\theta}\right)^{\alpha}\left(\frac{1-\alpha-\beta}{1-\theta-\gamma}\right)^{1-\alpha}\left(\frac{n}{l_{a t}^{*}}\right)^{\beta} A_{t}\right]^{1-\theta-\gamma}\left(\gamma^{\gamma} B_{t}\right)^{\alpha-1}\left(\frac{\theta}{G_{k}^{*} \rho^{-1}+\delta-1}\right)^{\alpha(1-\gamma)-\theta}\right\}^{\frac{1}{1-\theta-\alpha \gamma}}$.

Both $k_{m t}^{*}$ and $p_{t}^{*}$ are increasing in $n$. Therefore, in the closed economy larger amounts of land have always positive effects on the stock of capital and on total output.

Regarding the convergence speed for the developed world, it can be shown that equilibrium conditions imply that the Jacobean matrix of the normalized dynamic system at the steady state does not depend on $n_{t}$, hence neither does the convergence speed of the closed economy.

\section{Equilibrium, steady-state growth, normalized variables, and the equation system}

Definition 1 The equilibrium of the world (closed) economy is a sequence of prices $\left\{p_{t}, r_{k t}, r_{n t}, w_{t}\right\}$, consumptions, investments and capital stocks $\left\{c_{a t}, c_{m t}, x_{t}, k_{t}\right\}$, and production plans $\left\{y_{a t}, k_{a t}, n_{a t}, l_{a t}\right\}$ and $\left\{y_{m t}, k_{m t}, z_{m t}, l_{m t}\right\}$, such that:

1. Given prices $\left\{p_{t}, r_{k t}, r_{n t}, w_{t}\right\}$, the consumptions, investments and capital stocks $\left\{c_{a t}, c_{m t}, x_{t}, k_{t}\right\}$ satisfy the utility maximization conditions (2) to (5), for given $N>0, k_{0}>0$.

2. Given prices $\left\{p_{t}, r_{k t}, r_{n t}, w_{t}\right\}$, the production plans $\left\{y_{a t}, k_{a t}, n_{a t}, l_{a t}\right\}$ and $\left\{y_{m t}, k_{m t}, z_{m t}, l_{m t}\right\}$ satisfy the profit maximization and zero profit conditions (11) to (14).

3. The consumptions, investments and capital stocks $\left\{c_{a t}, c_{m t}, x_{t}, k_{t}\right\}$, and the production plans $\left\{y_{a t}, k_{a t}, n_{a t}, l_{a t}\right\}$ and $\left\{y_{m t}, k_{m t}, z_{m t}, l_{m t}\right\}$ satisfy the feasibility conditions (6) to (10), (36) and (37), given $G_{A}, G_{B} \geq 1$ and $A_{0}=B_{0}=E>0$. 
For the small-open developing nation, in turn, equilibrium is provided by the same equations but replacing (36) and (37) with the balanced product-trade condition

$$
l_{a t} y_{a t}+(1-\gamma) p_{t} l_{m t} y_{m t}=c_{a t}+p_{t}\left(c_{m t}+x_{t}\right),
$$

taking as exogenous the steady state relative price of output of the world economy.

Definition A diversified-production equilibrium of the small open economy is a sequence of prices $\left\{p_{t}, r_{k t}, r_{n t}, w_{t}\right\}$, consumptions, investments and capital stocks $\left\{c_{a t}, c_{m t}, x_{t}, k_{t}\right\}$, and production plans $\left\{y_{a t}, k_{a t}, n_{a t}, l_{a t}\right\}$ and $\left\{y_{m t}, k_{m t}, z_{m t}, l_{m t}\right\}$, such that:

1. The sequence of prices $\left\{p_{t}\right\}$ satisfies (45) at every period $t$.

2. Given prices $\left\{p_{t}, r_{k t}, r_{n t}, w_{t}\right\}$, the consumptions, investments and capital stocks $\left\{c_{a t}, c_{m t}, x_{t}, k_{t}\right\}$ satisfy the utility maximization conditions (2) to (5).

3. Given prices $\left\{p_{t}, r_{k t}, r_{n t}, w_{t}\right\}$, the production plans $\left\{y_{a t}, k_{a t}, n_{a t}, l_{a t}\right\}$ and $\left\{y_{m t}, k_{m t}, z_{m t}, l_{m t}\right\}$ satisfy the profit maximization and zero profit conditions (11) to (14).

4. The consumptions, investments and capital stocks $\left\{c_{a t}, c_{m t}, x_{t}, k_{t}\right\}$, and the production plans $\left\{y_{a t}, k_{a t}, n_{a t}, l_{a t}\right\}$ and $\left\{y_{m t}, k_{m t}, z_{m t}, l_{m t}\right\}$ satisfy the balanced trade condition (46) and the feasibility conditions (6) to (10), given $G_{A}, G_{B} \geq 1$ and $A_{0}=B_{0}=E>0$.

Growth rates along the balanced growth path in the developed world and the developing country coincide. In particular, conditions (8) to (10) imply that $G_{l_{a}}^{*}=G_{l_{m}}^{*}=0, G_{k_{a}}^{*}=$ $G_{k_{m}}^{*}=G_{k}^{*}=G_{x}^{*}$. Expression (22) says that $G_{y}^{*}=G_{y_{a}}^{*}=G_{p}^{*} G_{y_{m}}^{*}$. Budget constraint (2) and equation (3) imply, in turn, the following steady-state conditions: $G_{c}^{*}=G_{c_{a}}^{*}=$ $G_{p}^{*} G_{c_{m}}^{*}=G_{p}^{*} G_{x}^{*}=G_{p}^{*} G_{k}^{*}=G_{w}^{*}$, and $G_{r_{k}}^{*}=G_{p}^{*}$. This and production functions (6) and (7) give the growth rate for output and prices as $G_{y}^{*}=\left(G_{A}^{1-\theta} G_{B}^{\alpha}\right)^{1 /(1-\theta-\alpha \gamma)}$ and $G_{p}^{*}=$ $\left(G_{A}^{1-\theta-\gamma} / G_{B}^{1-\alpha}\right)^{1 /(1-\theta-\alpha \gamma)}$, respectively.

In order to obtain an equation system composed of variables that reach constant values at steady state, we carry out the following normalization suggested by the previous paragraph. We define $\hat{z}=z p /\left(A^{1-\theta} B^{\alpha}\right)^{1 /(1-\theta-\alpha \gamma)}$, for $z=k, y_{m}, c_{m}, x, k_{m}, k_{a}$. Let us also define $\hat{v}=$ $v /\left(A^{1-\theta} B^{\alpha}\right)^{1 /(1-\theta-\alpha \gamma)}$, for $v=y, c_{a}, y_{a}, c, w$. Finally, $\hat{p}=p\left(B^{1-\alpha} / A^{1-\theta-\gamma}\right)^{1 /(1-\theta-\alpha \gamma)}$ and $\hat{r}_{k}=r_{k} / p$.

In terms of the normalized variables, the above system for the developed world can be written as:

$$
\begin{gathered}
\frac{\hat{c}_{t+1}}{\hat{c}_{t}}\left(G_{A}^{\gamma} G_{B}\right)^{\frac{1}{1-\theta-\alpha \gamma}}=\frac{\hat{p}_{t+1}}{\hat{p}_{t}} \rho\left(\hat{r}_{k t+1}+1-\delta\right), \quad \text { with } \hat{r}_{k t}=\theta\left(\hat{p}_{t}^{1-\theta} \gamma^{\gamma} \hat{k}_{m t}^{\theta+\gamma-1}\right)^{\frac{1}{1-\gamma}} \\
\hat{k}_{t+1}\left(G_{A}^{\gamma} G_{B}\right)^{\frac{1}{1-\theta-\alpha \gamma}} \frac{\hat{p}_{t}}{\hat{p}_{t+1}}=(1-\delta) \hat{k}_{t}+\hat{r}_{k t} \hat{k}_{t}+\hat{w}_{t}-\hat{c}_{t}+(1-\alpha-\beta)^{\frac{1-\alpha-\beta}{\beta}}\left(\frac{\alpha \hat{k}_{m t}}{\theta \hat{p}_{t}}\right)^{\frac{\alpha}{\beta}}(1-\theta-\gamma)^{\frac{\alpha}{\beta}} \beta n \hat{w}_{t}^{\frac{\beta-1}{\beta}} \\
\hat{w}_{t}=(1-\theta-\gamma)\left(\hat{p}_{t}^{1-\theta} \gamma^{\gamma} \hat{k}_{m t}^{\theta}\right)^{\frac{1}{1-\gamma}}
\end{gathered}
$$




$$
\begin{gathered}
\hat{k}_{t}=\hat{k}_{m t}\left[\frac{\alpha}{\theta}\left(1-l_{m t}\right) \frac{1-\theta-\gamma}{1-\alpha-\beta}+l_{m t}\right] \\
\hat{p}_{t}=\gamma^{-\gamma}\left[\left(\frac{\alpha}{\theta}\right)^{\alpha}\left(\frac{1-\alpha-\beta}{1-\theta-\gamma}\right)^{1-\alpha}\left(\frac{n}{1-l_{m t}}\right)^{\beta}\right]^{1-\gamma} \hat{k}_{m t}^{\alpha(1-\gamma)-\theta} \\
\frac{(1-\theta-\gamma)\left(1-l_{m t}\right)}{(1-\alpha-\beta)\left(l_{m t}-\frac{\theta \hat{x}_{t}}{\hat{r}_{k t} \hat{k}_{m t}}\right)}=\frac{\varphi}{1-\varphi} \\
\text { given } G_{L}, G_{A}, G_{B} \geq 1, E>0 .
\end{gathered}
$$

Definition 3 A steady state normalized equilibrium of the world (closed) economy is prices $\left\{\hat{p}^{*}, \hat{r}_{k}^{*}, \hat{r}_{n}^{*}, \hat{w}^{*}\right\}$, consumptions, investment and capital stock $\left\{\hat{c}_{a}^{*}, \hat{c}_{m}^{*}, \hat{x}^{*}, \hat{k}^{*}\right\}$, production plans $\left\{\widehat{y}_{a}^{*}, \hat{k}_{a}^{*}, n_{a}^{*}, l_{a}^{*}\right\}$ and $\left\{\widehat{y}_{m}^{*}, \hat{k}_{m}^{*}, \widehat{z}_{m}^{*}, l_{m}^{*}\right\}$, for given $N$, that satisfy the normalized equilibrium conditions of the world economy.

Similarly, the normalized dynamic system of equations for the small open economy will be given by (47) to (51), (53), and $\hat{p}_{t}=\hat{p}^{*}$.

Definition 4 A steady state normalized diversified-production equilibrium of the small open economy is $\left\{\hat{p}^{*}, \hat{r}_{k}, \hat{r}_{n}, \hat{w}\right\}$, consumptions, investment and capital stock $\left\{\hat{c}_{a}, \hat{c}_{m}, \hat{x}, \hat{k}\right\}$, production plans $\left\{\widehat{y}_{a}, \hat{k}_{a}, n_{a}, l_{a}\right\}$ and $\left\{\widehat{y}_{m}, \hat{k}_{m}, \widehat{z}_{m}, l_{m}\right\}$, for given $N$, that satisfy the normalized equilibrium conditions of the small open economy.

The asymptotic speed of convergence For the developing economy, for which $\hat{p}_{t}=\hat{p}^{*}$, equations (47) and (51) imply the following Euler equation for normalized consumption under diversified production, given the calibration assumption that $G_{k}=G_{y}$ :

$$
\hat{c}_{t+1}=\hat{c}_{t} G_{k}^{-1} \rho\left[\hat{r}_{k t+1}+1-\delta\right]
$$

where $\hat{r}_{k t+1}=\theta\left(\hat{p}^{* 1-\theta} \gamma^{\gamma} \hat{k}_{m t+1}^{\theta+\gamma-1}\right)^{\frac{1}{1-\gamma}}$ and $\hat{k}_{m t+1}=f\left(\hat{k}_{t+1}, n\right)$ is the implicit solution to

$$
\hat{k}_{m}^{1+\frac{\alpha-\theta /(1-\gamma)}{\beta}}+\Lambda\left(n, \hat{p}^{*}\right)\left(\hat{k}-\hat{k}_{m}\right)=0
$$

Where

$$
\Lambda\left(n, \hat{p}^{*}\right)=\frac{n^{-1} \hat{p}^{* \frac{1+\alpha(1-\gamma)-\theta}{\beta(1-\gamma)}} \gamma^{\gamma / \beta(1-\gamma)}\left(\frac{\theta}{\alpha}\right)^{\alpha / \beta}\left(\frac{1-\theta-\gamma}{1-\alpha-\beta}\right)^{(1-\alpha) / \beta}}{1-\alpha(1-\theta-\gamma) /(\theta(1-\alpha-\beta)}
$$

Expression (55) comes from combining (50) to (51).

From equations (48) to (50), and (51), the law of motion for normalized capital per worker is

$$
\hat{k}_{t+1}=G_{k}^{-1}\left[\hat{y}_{t}-\hat{c}_{t}+(1-\delta) \hat{k}_{t}\right]
$$


where, under diversified production, normalized output is

$$
\hat{y}_{t}=\frac{1-\theta-\gamma}{1-\alpha-\beta}\left(\hat{p}^{* 1-\theta} \gamma^{\gamma} \hat{k}_{m t}^{\theta}\right)^{\frac{1}{1-\gamma}}\left[1+l_{m t}\left(\frac{\theta-(\alpha+\beta)(1-\gamma)}{1-\theta-\gamma}\right)\right]
$$

and the labor allocation to the non-primary sector is

$$
l_{m t}=1-n \frac{\left(\frac{\alpha}{\beta}\right)^{\frac{\alpha}{\beta}}\left(\frac{1-\alpha-\beta}{1-\theta-\gamma}\right)^{\frac{(1-\alpha)}{\beta}}}{\hat{p}^{* \frac{1+\alpha(1-\gamma)-\theta}{\beta(1-\gamma)}} \gamma \gamma / \beta(1-\gamma)} \hat{k}_{m t}^{\frac{\alpha(1-\gamma)-\theta}{\beta(1-\gamma)}}
$$

As in previous literature, we next linearize the dynamic system described by expressions (54) and (56) around the steady state to get $\hat{c}_{t+1}=\Phi\left(\hat{k}_{t}, \hat{c}_{t} ; n\right)$ and $\hat{k}_{t+1}=\Psi\left(\hat{k}_{t}, \hat{c}_{t} ; n\right)$. The asymptotic speed of convergence of income per capita in our discrete time model is given by

$$
-\frac{\left(G_{y}^{*} \hat{y}_{t+1}-\hat{y}_{t}\right)-\left(G_{y}^{*} \hat{y}^{s s}-\hat{y}^{s s}\right)}{\hat{y}_{t}-\hat{y}^{s s}}=1-\lambda G_{y}^{*}
$$

where $\lambda$ is the stable root of the linearized dynamic system associated to equations (54) and (56) under diversified production. This exercise also reveals that the transition is characterized by a one-dimensional stable saddle-path, which in turn implies that the adjustment path is asymptotically stable and unique. The linearization around the steady state equilibrium implies that $\lambda=\frac{1}{2}\left(\Psi_{k}^{*}+\Phi_{c}^{*}-\Delta^{1 / 2}\right)$, with $\Delta=\left(\Psi_{k}^{*}-\Phi_{c}^{*}\right)^{2}+4 \Psi_{c}^{*} \Phi_{k}^{*}$, where the subscripts stand for partial derivatives and the asterisk means steady state value. The slope of the saddle path at the steady state is $\left(\Psi_{k}^{*}-\lambda\right) /\left(-\Psi_{c}^{*}\right)$. In all numerical experiments, in a diversified production equilibrium: $\Delta>0,2>\Psi_{k}^{*}>\Phi_{c}^{*}=1 ; \Psi_{c}^{*}, \Phi_{k}^{*} \in(-1,0) ; \Psi_{k}^{*}, \Psi_{c}^{*}$ and $\Phi_{c}^{*}$ don't depend on $n$, but $\frac{\partial \Phi_{k}^{*}}{\partial n}<0$ if $\alpha<\theta /(1-\gamma), \frac{\partial \Phi_{k}^{*}}{\partial n}>0$ if $\alpha>\theta /(1-\gamma)$ and $\frac{\partial \Phi_{k}^{*}}{\partial n}=0$ if $\alpha=\theta /(1-\gamma)$. Moreover, the sign of $\frac{\partial \Phi_{k}^{*}}{\partial n}$ is the same as the sign of the response of $\partial \hat{r}_{k t+1} / \partial \hat{k}_{t}$ to changes in $n$ :

$$
\begin{gathered}
\frac{\partial \hat{r}_{k t+1}}{\partial \hat{k}_{t}}=\frac{\partial \hat{r}_{k t+1}}{\partial \hat{k}_{m t+1}} \frac{\partial \hat{k}_{m t+1}}{\partial \hat{k}_{t+1}} \Psi_{k}^{*} \\
\frac{\partial^{2} \hat{r}_{k t+1}}{\partial \hat{k}_{t} \partial n}=\frac{\left(\hat{p}^{* 1-\theta} \gamma^{\gamma}\right)^{\frac{1}{1-\gamma}}\left(\frac{\theta+\gamma-1}{1-\gamma}\right)}{\hat{k}_{m t}^{1-\frac{\theta+\gamma-1}{1-\gamma}}}\left(\frac{\left(\frac{\theta+\gamma-1}{1-\gamma}-1\right)\left(\frac{\partial \hat{k}_{m t+1}}{\partial \hat{k}_{t+1}}\right)^{2}}{\hat{k}_{m t}} \frac{\partial k^{*}}{\partial n}+\frac{\partial^{2} \hat{k}_{m t+1}}{\partial \hat{k}_{t+1} \partial n}\right) \Psi_{k}^{*},
\end{gathered}
$$

where $\hat{r}_{k t+1}=r_{k}\left(f\left(\hat{k}_{t+1}, n\right)\right)$ is evaluated at the implicit solution given by $(55)$, so $\frac{\partial \hat{k}_{m t+1}}{\partial \hat{k}_{t+1}}>$ $0, \frac{\partial \hat{k}_{m t+1}}{\partial n}>0$ if $\alpha<\theta /(1-\gamma), \frac{\partial \hat{k}_{m t+1}}{\partial n}<0$ if $\alpha>\theta /(1-\gamma), \frac{\partial \hat{k}_{m t+1}}{\partial n}=0$ if $\alpha=\theta /(1-\gamma)$, and $\hat{k}_{t+1}=\Psi\left(\hat{k}_{t}, \hat{c}_{t} ; n\right)$. The first and second terms inside the brackets of $(60)$ are related to the capital-share and capital-accumulation effects explained in the text, respectively. Moreover, $\operatorname{sign}\left(\frac{\partial k^{*}}{\partial n}\right)=\operatorname{sign}(\alpha-\theta /(1-\gamma)-\alpha)=-\operatorname{sign}\left(\partial^{2} \hat{k}_{m t+1} / \partial \hat{k}_{t+1} \partial n\right)$. The effect of $n$ on $\lambda$ can be written as 


$$
\frac{\partial \lambda}{\partial n}=-\frac{\Psi_{c}^{*}}{\Delta^{1 / 2}} \frac{\partial \Phi_{k}^{*}}{\partial n}<0 \text { iff } \frac{\partial \Phi_{k}^{*}}{\partial n}<0
$$

From (58) the effect of the natural input on the speed of convergence is $-G_{y}^{*} \partial \lambda / \partial n$, so the speed rises with $n$ if $\alpha<\theta /(1-\gamma)$, falls if $\alpha>\theta /(1-\gamma)$ and remains constant if $\alpha=\theta /(1-\gamma)$. 


\section{References}

Adamopoulos, T., "Land Inequality and the Transition to Modern Growth," Review of Economic Dynamics 11(2), 2008.

Alexeev, M., and R. Conrad, "The Elusive Curse of Oil," Review of Economics and Statistics 91(3): 586-98, 2009.

Atkeson, A., and P. Kehoe, "Paths of development for early- and late-bloomers in a Dynamic Heckscher-Ohlin Model," Federal Reserve Bank of Minneapolis working paper, 2000.

Bajona, C., and T.J. Kehoe, "Demographics in a Dynamic Heckscher-Ohlin Model," NBER Working Paper 12566, 2006.

Bajona, C., and T.J. Kehoe, "Trade, Growth and Convergence in a Dynamic HeckscherOhlin Model," Review of Economic Dynamics 13: 487-513, 2010.

Barro, R.J., and X. Sala-i-Martin, Economic Growth, New York, Macmillan, 1995.

Bhagwati, J., "Immiserizing Growth: A Geometrical Note," Review of Economic Studies 25(3):201-205, June 1958.

Brunnschweiler, C.N., and E.H. Bulte, The Resource Curse Revisited and Revised: A Tale of Paradoxes and Red Herrings," Journal of Environmental Economics and Management, $55: 248-264,2008$.

Caselli, F., and T. Cunningham, "Leader Behavior and the Natural Resource Curse," Oxford Economic Papers 61:628-650, 2009.

Caselli, F., G. Esquivel and F. Lefor, "Reopening the Convergence Debate: A New Look at Cross-Country Growth Empirics," Journal of Economic Growth 1, 363-91, 1996.

Corden, W.M., and J.P. Neary, "Booming Sector and De-Industrialisation in a Small Open Economy," Economic Journal, 92:825-848, December 1982.

Frankel, J.A., "The Natural Resource Curse: A Survey," NBER W.P. No. 15836, March 2010 .

Gaitan, B., and T.L. Roe, "International Trade, Exhaustible-Resource Abundance and Economic Growth," Review of Economic Dynamics, 15:72-93, 2012.

Galor, O., O. Moav and D. Vollrath, "Land Inequality and the Emergence of Human Capital Promoting Institutions," Review of Economic Studies 75, 2008.

Galor, O., and A. Mountford, "Trading Population for Productivity: Theory and Evidence", Review of Economic Studies 75(4): 1143-1179, October 2008.

Guilló, M.D., and F. Perez-Sebastian, "The Curse and Blessing of Fixed Specific Factors in Small-Open Economies," Journal of Development Economics, Vol. 82, 58-78, 2007.

Guilló, M.D., and F. Perez-Sebastian, "Convergence in a Dynamic Heckscher-Ohlin Model with Land" mimeo, University of Alicante, 2013.

Gylfason, T., "Natural Resources, Education, and Economic Development," European Economic Review 45: 847-859, 2001.

Hodler, R., "The Curse of Natural Resources in Fractionalized Countries," European Economic Review 50, no. 6, 1367-86, 2006.

Herrendorf, B., and A. Valentinyi, "Measuring Factor Income Shares at the Sectoral Level," Review of Economic Dynamics 11, 820-835, 2008. 
Irz, X., and T. Roe, "Seeds of Growth? Agricultural Productivity and the Transitional Dynamics of the Ramsey Model," European Review of Agricultural Economics 32(2): 143-165, 2005.

Isham, J., M. Woolcock, L. Pritchett, and G. Busby, "The Varieties of Resource Experience: Natural Resource Export Structures and the Political Economy of Economic Growth," World Bank Economic Review 19(2): 141-174, 2005.

James, A., "The Resource Curse: A Statistical Mirage?", Journal of Development Economics $114,55-63,2015$.

Jorgenson, D.W., and K.J. Stiroh, "Raising the Speed Limit: U.S. Economic Growth in the Information Age," Brookings Papers on Economic Activity 1, 125-211, 2000. On line data as Dale W. Jorgenson, 2007-09-22, "35 Sector KLEM", http://hdl.handle.net/1902.1/10684 UNF:3:TqM00zRqsatX2q/teT253Q== V1 [Version].

Kehoe, T.J., and K.J. Ruhl, "Are Shocks to the Terms of Trade Shocks to Productivity?" Review of Economic Dynamics 11, 804-819, 2008.

Matsuyama, K., "Agricultural Productivity, Comparative Advantage, and Economic Growth," Journal of Economic Theory 58: 317-334, December 1992.

Mehlum, H., K. Moene and R. Torvik, "Institutions and the Resource Curse," Economic Journal 116: 1-20, January 2006.

Mountford, A., "Trade, convergence and overtaking," Journal of International Economics 46: 167-182, 1998.

Papyrakis, E., and R. Gerlagh, "Resource Abundance and Economic Growth in the United States," European Economic Review 51, 1011-1039, 2007.

Rodriguez, F., and J.D. Sachs, "Why do Resource-Abundant Economies Grow More Slowly?" Journal of Economic Growth, 4:277-303, 1999.

Sachs, J.D., and A.M. Warner, "Fundamental Sources of Long-Run Growth," American Economic Review 87: 184-188, 1997.

Sachs, J.D., and A.M. Warner, "The big push, natural resource booms and growth," Journal of Development Economics 59: 43-76, 1999.

Sachs, J.D. and A.M. Warner, "The curse of natural resources," European Economic Review 45: 827-838, May 2001.

Stefanski, R., "Structural transformation and the oil price," Review of Economic Dynamics 17, 484-504, 2014.

van der Ploeg, F., "Natural Resources: Curse or Blessing?" Journal of Economic Literature 49, 366-420, 2011.

van der Ploeg, F., and S. Poelhekke, "The pungent smell of 'red herrings': subsoil assets, rents, volatility and the resource curse," Journal of Environmental Economics and Management 60, 44-55, 2010.

Ventura, J., "Growth and Interdependence," Quarterly Journal of Economics, 57-84, February 1997. 